\title{
Experimental Investigations of Polymer Hollow Fibre Heat Exchangers for Building Heat Recovery Application
}

\author{
Xiangjie Chen ${ }^{1}$, Yuehong Su${ }^{1}$, Devrim Aydin ${ }^{1}$, David Reay ${ }^{2}$, Richard Law ${ }^{2}$, Saffa Riffat ${ }^{1}$ \\ ${ }^{1}$ Department of Architecture and Built Environment, University of Nottingham, University \\ Park, NG7 2JQ, Nottingham. United Kingdom \\ ${ }^{2}$ David Reay \& Associates, United Kingdom
}

Contact: Xiangjie Chen; Email:xiangjie.chen@nottingham.ac.uk

\begin{abstract}
Due to low cost, light weight and corrosion resistant features, polymer heat exchangers have been extensively studied by researchers with the aim to replace metallic heat exchangers in a wide range of applications. Although the thermal conductivity of polymer material is generally lower than the metallic counterparts, the large specific surface area provided by the polymer hollow fibre heat exchanger (PHFHE) offers the same or even better heat transfer performance with smaller volume and lighter weight compared with the metallic shell-and-tube heat exchangers. This paper presents the construction and experimental investigations of polypropylene based polymer hollow fibre heat exchangers in the form of shell-and-tube. The measured overall heat transfer coefficients of such PHFHEs are in the range of $258-1675 \mathrm{~W} / \mathrm{m}^{2} \mathrm{~K}$ for water to water application. The effects of various parameters on the overall heat transfer coefficient including flow rates and numbers of fibres, the effectiveness of heat exchanger, the number of heat transfer unit (NTU), and the height of transfer unit (HTU) are also discussed in this paper. The results indicate that the PHFHEs could offer a conductance per unit volume of $4 * 10^{6} \mathrm{~W} / \mathrm{m}^{3} \mathrm{~K}$, which is $2 \sim 8$ times higher than the conventional metal heat exchangers. This superior thermal performance together with its low cost, corrosive resistant and light weight features make PHFHEs potentially very good substitutes for metallic heat recovery system for building application.
\end{abstract}

Key words: Polymer hollow fibre, heat recovery, heat exchanger, heat transfer, experimental testing

\section{Nomenclature}

A Heat transfer area $\left(\mathrm{m}^{2}\right)$

$C_{p} \quad$ Specific heat $(\mathrm{J} / \mathrm{Kg} \mathrm{K})$

CUV Conductance per unit volume $\left(\mathrm{W} / \mathrm{m}^{3} \mathrm{~K}\right)$

D Tube/shell diameter (m)

$\mathrm{Gz} \quad$ Graetz number

HTU Height of transfer unit (m or $\mathrm{cm}$ )

$34 k$ Thermal conductivity $(\mathrm{W} / \mathrm{mK})$

L Length (m) 
$36 \dot{m} \quad$ Mass flow rate $(\mathrm{kg} / \mathrm{s})$

$37 \mathrm{~N}$ Number of fibres inside the heat exchanger

38 NTU Number of heat transfer unit

$39 \mathrm{Nu} \quad$ Nusselt number

$40 \Delta \mathrm{P} \quad$ Pressure drop $(\mathrm{Pa})$

$41 \quad$ Pr Prandtle number

$42 \quad Q \quad$ Heat transfer rate (W)

$43 \quad \dot{V} \quad$ Volumetric flow rate $\left(\mathrm{m}^{3} / \mathrm{s}\right)$

$44 \mathrm{R} \quad$ Thermal resistance $\left(\mathrm{m}^{2} / \mathrm{KW}\right)$

$45 \quad \operatorname{Re} \quad$ Reynolds number

46 St Stanton number

$47 \quad T \quad$ Temperature $\left({ }^{\circ} \mathrm{C}\right)$

$48 \quad U \quad$ Overall heat transfer coefficient $\left(\mathrm{W} / \mathrm{m}^{2} \mathrm{~K}\right)$

$49 \quad V \quad$ Volume $\left(\mathrm{m}^{3}\right)$

50

51 Greek Letters/Subscripts

$52 \alpha \quad$ Surface to volume ratio $\left(\mathrm{m}^{2} / \mathrm{m}^{3}\right)$

53 c,i Cold side inlet

54 c,o Cold side outlet

$55 \quad \varepsilon \quad$ Heat exchanger effectiveness

56 i Inside

$57 \lambda \quad$ Packing fraction of a PHFHE equals to $N D_{0}{ }^{2} / D_{S}{ }^{2}$

58 h,i Hot side inlet

59 h,o Hot side outlet

$60 \mathrm{~lm}$ Logarithmic mean

61 o Outside

62 ov Overall

$63 \rho \quad$ Density of the fluid $\left(\mathrm{kg} / \mathrm{m}^{3}\right)$

64 S Shell side 
Tube side

$\mathrm{u} \quad$ Linear velocity inside the tube $(\mathrm{m} / \mathrm{s})$

$67 \mu \quad$ Dynamic viscosity of the fluid $(\mathrm{kg} / \mathrm{ms})$

W

Wall

\section{Introduction}

In the era of rapid global economic development, the growing world energy use has triggered problems such as primary energy supply difficulties and world-wide environmental concerns (carbon emission, global warming, air pollution, etc). In developed countries, the energy consumption of buildings account for $20-40 \%$ of the total final energy consumption ${ }^{1}$. Heat recovery systems ${ }^{2}$ in the form of air ventilation systems ${ }^{3-5}$, membrane heat exchangers ${ }^{6,7}$, metal heat exchanger ${ }^{8,9}$ have been extensively studied by researchers with the aim to improve energy efficiency and reduce energy costs for building applications. Most of such heat recovery systems are made from metallic materials, which have the disadvantages in terms of weight and cost. In addition, specially treated metal heat exchanger is needed if the working fluids are corrosive. Moreover, the manufacturing process of metal materials consumes significant amount of primary energies, accompanied by carbon emissions. Given these considerations, it is desirable to find an alternative material for heat exchangers that can overcome these disadvantages and also acquire comparable heat exchange efficiency and be easily fabricated. This is where the use of polymer heat exchanger comes into place. With the advantages of greater fouling and corrosion resistance, greater geometric flexibility and ease of manufacturing, reduced energy of formation and fabrication, and the ability to handle liquids and gases (i.e, single and two-phase duties), polymer heat exchangers have been widely studied and applied in the field of evaporative cooling system ${ }^{10,11}$, micro-electronic cooling devices $^{12,13}$, water desalination systems ${ }^{14,15}$, solar water heating systems ${ }^{16,17}$, liquid desiccant cooling systems ${ }^{18,19}$, etc. The detailed research progresses and various applications of polymer hollow fibre heat exchanger can be found in the review paper ${ }^{20}$. Most importantly, polymer materials can offer substantial weight, space, and volume savings, which make them more competitive compared with heat exchangers manufactured from many metallic alloys. Moreover, the energy required to produce a unit mass of polymers is about two times lower than common metals, making them environmentally attractive ${ }^{21}$.

One of the drawbacks of polymer materials are their relatively low thermal conductivities, typically in the range of 0.1 to $0.4 \mathrm{~W} / \mathrm{m}^{2} \mathrm{~K}$, which is about 100-200 times lower than the metal materials. In order to overcome this obstacle and increase the thermal performance of polymer heat exchanger, researchers have studied the polymer heat exchangers with various configurations: gas to air heat exchanger with triangular channels ${ }^{22}$, shell and tube or immersion coil fluoropolymer heat exchanger ${ }^{23}$, air to water heat exchanger with rectangular channel plate ${ }^{24}$, plastic falling-film evaporator ${ }^{25}$. But the overall heat transfer coefficients achieved were still very low, which were in the range of $341-567 \mathrm{~W} / \mathrm{m}^{2} \mathrm{~K}$, with the fibre outside diameter between $2.54 \mathrm{~mm}$ and $9.53 \mathrm{~mm}$. 
The relatively low overall heat transfer coefficients can be improved and reach values comparable to metal heat exchangers, when the heat exchanger is made from polymer microhollow fibre with fibre wall thickness below $100 \mu \mathrm{m}^{25}$. Several researches have been focused on the heat transfer mechanism of polymer micro-hollow fibre heat exchangers (PHFHE), with inside and outside diameter (ID and OD) less than $0.1 \mathrm{~mm}$. Bourouni et al. ${ }^{26}$ presented experimental data on a falling film evaporator and condenser made of $2.5 \mathrm{~cm}$ diameter circular PP tubes (wall thickness of $5 \mathrm{~mm}$ ) used in an 'aero-evapo-condensation process' for desalination. The results showed that for the same thermal performance, such polymer heat exchanger was 2-3 times cheaper than its metal counterpart. Zarkadas and Sirkar ${ }^{27}$ reported polymeric hollow fibre heat exchangers (PHFHE) for low temperature (up to $150-200{ }^{\circ} \mathrm{C}$ ) applications. The overall heat transfer coefficients for the water-water, ethanol-water, and steam-water systems reached $647-1314,414-642$, and $2000 \mathrm{~W} /\left(\mathrm{m}^{2} \mathrm{~K}\right)$, respectively. An olefin/paraffin distillation system using hollow fibre structured packings (HFSP) was proposed by Yang et al. ${ }^{28}$. This group of researchers recently scaled up the experiment and long-term operational testing results were obtained and reported (Yang et al. ${ }^{29}$ ). The results demonstrated that after long-term exposure to light hydrocarbon environments $\left(\leq 70{ }^{\circ} \mathrm{C}\right)$, the mechanical properties of the PP polymer did not degrade significantly. Astrouski I. et al. ${ }^{30}$ studied the fouling effect of polymeric heat exchanger made from PP (inner and out fibre diameter of $0.461 \mathrm{~mm}$ and $0.523 \mathrm{~mm}$ respectively) for the purpose of cooling $\mathrm{TiO}_{2}$ suspension. The experimental test results showed a very high overall heat transfer coefficient, with up to $2100 \mathrm{~W} / \mathrm{m}^{2} \mathrm{~K}$ for clean conditions and $1750 \mathrm{~W} / \mathrm{m}^{2} \mathrm{~K}$ for dirty conditions at the flow velocity of $0.05 \mathrm{~m} / \mathrm{s}$. Zhao et al. ${ }^{31}$ presented a numerical analysis of a novel PP hollow fibre heat exchanger for low temperature applications using FLUENT. The heat transfer coefficient of PP fibres was predicted to be achieved at $1109 \mathrm{~W} / \mathrm{m}^{2} \mathrm{~K}$ with inside and outside fibre diameters of $0.6 \mathrm{~mm}$ and $1 \mathrm{~mm}$ respectively.

The lack of extensive experience and testing data for polymer hollow fibre plastic heat exchanger and the unwillingness of industry partners to depart from well established metal heat exchanger remain to be big barriers for the wide applications of this technology. With the aim to experimentally investigate the effects of various working flow rates and number of fibres on the overall heat transfer coefficients, and to validate the theoretical simulation model developed by the authors, three different modules of polymer hollow fibre heat exchanger (fibre ID of $450 \mu \mathrm{m}$ and OD of $550 \mu \mathrm{m}$ ) were fabricated and tested in the laboratory testing conditions. The effects of various parameters on the overall heat transfer coefficient including flow rates, numbers of fibres, the effectiveness of heat exchanger, the number of heat transfer unit (NTU), and the height of transfer unit (HTU) are discussed in this paper. The experimental obtained overall heat transfer coefficient and overall conductance per unit volume for PHFHE are compared with these of metal heat exchangers. The experimental uncertainties occurred associated with the measurement of flow rates and working fluid temperatures, etc. are also analysed.

\section{Theory}


145 Assuming there is no heat loss to the surrounding, the overall heat transfer rate Q, between 146 the shell side and tube side fluids, is defined by the flow rates of the hot and cold fluids flow 147 rates and their inlet and outlet temperatures, as shown in the following equation:

$Q=\dot{m}_{t} c_{p, t}\left(\mathrm{~T}_{\mathrm{c}, \mathrm{o}}-\mathrm{T}_{\mathrm{c}, \mathrm{i}}\right)=\dot{m}_{s} c_{s}\left(\mathrm{~T}_{\mathrm{h}, \mathrm{i}}-\mathrm{T}_{\mathrm{h}, \mathrm{o}}\right)$

149 Where subscript $t$ denotes tube side and $s$ denotes shell side.

150 The overall heat transfer coefficient $\mathrm{U}$, can be given by:

151

$\mathrm{U}=Q /\left(\mathrm{A} \Delta T_{l m}\right)$

Where $\mathrm{Q}$ is an average heat transfer rate value between two fluids;

$153 \mathrm{~A}$ is the heat transfer area (for hollow fibre heat exchanger, $\mathrm{A}$ is the total inside surface area 154 of the hollow fibres);

$\Delta T_{l m}$ is the logarithmic mean temperature difference (LMTD), and is defined as:

$156 \Delta \mathrm{T}_{\mathrm{lm}}=\frac{\Delta \mathrm{T} 1-\Delta \mathrm{T} 2}{\ln [\Delta \mathrm{T} 1 / \Delta \mathrm{T} 2]}$

157 Here $\Delta \mathrm{T} 1$ and $\Delta \mathrm{T} 2$ are the temperature differences between two fluids at each end of a heat exchanger. In our case, for counter-flow heat exchanger

160 The heat exchanger effectiveness $\varepsilon$, number of transfer unit (NTU) and the height of transfer 161 unit (HTU) can be calculated using the following equations ${ }^{32}$ :

$\varepsilon=\frac{U_{i} A_{i}}{C_{\min }} \frac{\Delta \mathrm{T}_{\mathrm{lm}}}{\mathrm{T}_{\mathrm{h}, \mathrm{i}}-\mathrm{T}_{\mathrm{c}, \mathrm{i}}}$

$163 \mathrm{NTU}=\frac{U_{i} A_{i}}{C_{\min }}=\frac{U_{o} A_{o}}{C_{\min }}$

$164 \mathrm{HTU}=\mathrm{L} / \mathrm{NTU}$

165 Where $\mathrm{L}$ is the length of the heat exchanger and $\mathrm{C}_{\min }$ is given by:

$166 C_{\min }=\left\{\dot{m}_{t} C_{t}, \dot{m}_{s} C_{s}\right\}_{\min }$

167 The performance comparison between PHFHEs and existing metal heat exchangers should be 168 made on a volumetric basis, so the so-called overall conductance per unit volume ${ }^{14}$ (CUV) is 169 defined, which is the product of the heat transfer coefficient and the surface to volume ratio $\alpha$ : 
171 CUV in this case expresses the total amount of heat transferred per unit time and unit volume.

172 A higher CUV value indicates a more compact heat exchanger which can offer the same 173 thermal performance, or a heat exchanger that transfers more heat for the same heat 174 exchanger volume.

175 The surface to volume ratio $\alpha$ of the PHFHE is the ratio between the fibre inside area to the 176 volume of the heat exchanger, which can be calculated by:

$177 \quad \alpha=\frac{A_{i}}{V}=\frac{4 N D_{i}}{D_{S}{ }^{2}}$

178 In fluid dynamics, the Graetz number $(\mathrm{Gz})$ is a dimensionless number that 179 characterizes laminar flow in a conduit. This number is useful in determining the thermally 180 developing flow entrance length in ducts. As stated by Hewit et al. ${ }^{33}$, small values of $\mathrm{Gz}(\mathrm{Gz}$ $181<20)$ indicates that radial temperature profiles are fully developed inside the laminar flow 182 tube. The Gz number is defined as:

183

$G_{z}=\frac{D_{H}}{L} R e P r$

184 Where

$185 D_{H}$ is the diameter in round tubes or hydraulic diameter in arbitrary cross-section ducts (m);

$186 L$ is the length;

187 Re is the Reynolds number and

188 Pr is the Prandtl number.

189

190

The theoretical tube side pressure drop for a PHFHE can be calculated based on Darcy-

191

Weisban Equation as stated by ${ }^{34}$ :

$192 \Delta P=f L \frac{\rho u^{2}}{2 d_{h}}$

Where $f$ is the flow resistance, also known as friction factor;

$194 \Delta \mathrm{P}$ is the pressure drop of the tube side for PHFHE;

$195 \rho$ is the density of the water.

196 The shell side and tube side Reynolds number are calculated using following equation:

$197 R e=\frac{D * G}{\mu}$

Where, D is fiber inside/outside diameter for tube/shell side Reynolds number; $\mu$ is dynamic viscosity of the tube/shell side fluid for tube/shell side Reynolds number ; 
$G$ is fluid mass velocity at the center line of the heat exchanger, detailed calculations could be referred to $\operatorname{Kern}^{35}$.

The relationship between the tube side Reynolds number and tube side linear velocity is described by Kern ${ }^{35}$ as following:

$$
R e_{t}=\frac{\rho * D_{i} * u_{t}}{\mu}
$$

The relationship between the shell side Reynolds number ${ }^{35}$ and shell side linear velocity can be found in ${ }^{35}$ as following:

$$
R e_{s}=\frac{\rho * D_{o} * u_{s}}{\mu}
$$

\section{Apparatus and procedure}

Polypropylene (PP) hollow fibres (manufactured by ZENA Ltd.) with outside diameter of $550 \mu \mathrm{m}$ and inside diameter of $450 \mu \mathrm{m}$ were used for the fabrication of three modules, with their geometrical information listed in Table 1 . The shell side tube diameter was $15 \mathrm{~mm}$ for Module 1 and Module 2 and $22 \mathrm{~mm}$ for Module 3. The three modules were fabricated in following way: The two ends of the fibres in a bundle were glued together first using PTFE resin. The fibre bundle was then inserted into a plastic tubing which was connected by two tee fittings, as shown in Figure 1. The fibre bundle was sealed with the two ends of the plastic tubing and the excessive length of fibres was cut. The two ends of the plastic tubing can be connected with a water loop, so they serve as the inlet and outlet of one water flow. The tube side hot water and shell side cooling water are in the counter flow direction. The detailed images and testing rig of PHFHE modules could be found in Figure 1.

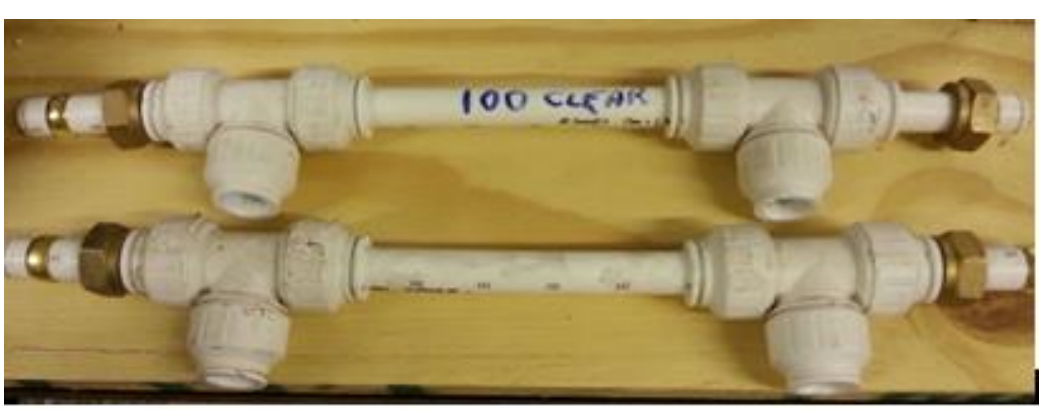

A: PHFHE heat exchanger (fibre number: 100 and 200)

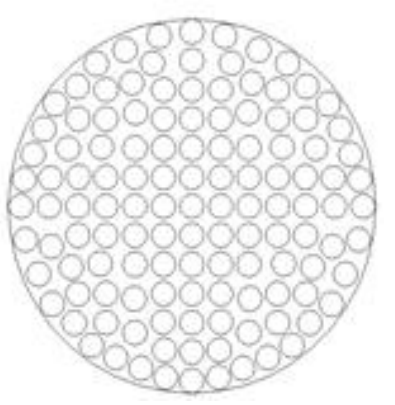

B: PHFHE heat exchanger cross section view (not to scale)

Figrue 1-a PHFHE heat exchanger 


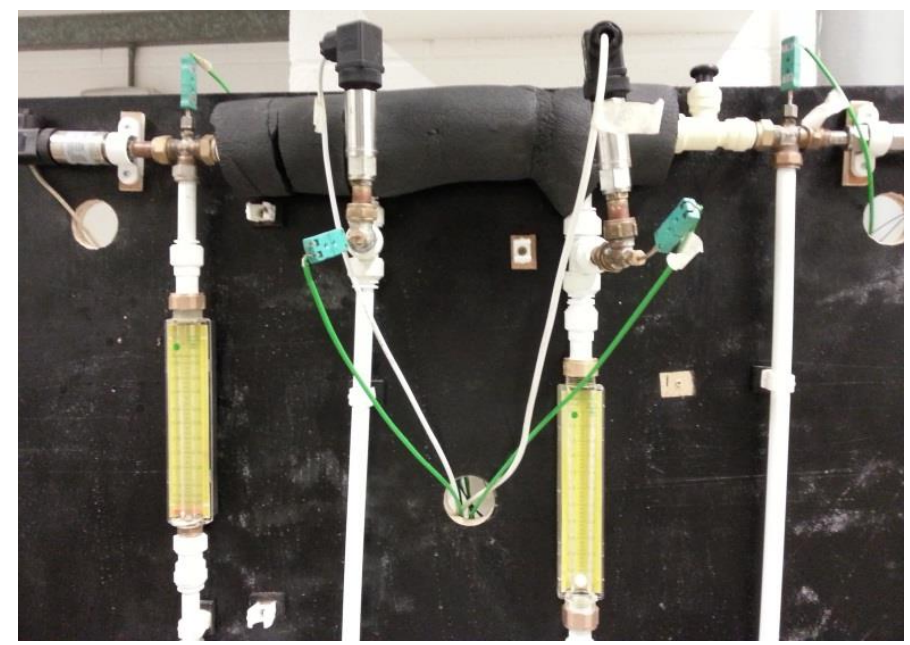

Figure 1-b PHFHE heat transfer measurement testing rig

Table 1 Geometrical Characteristic of PHFHE

\begin{tabular}{|l|l|l|l|l|l|l|}
\hline Module & $\begin{array}{l}\text { Fibre } \\
\text { number } \\
(\mathrm{N})\end{array}$ & $\begin{array}{l}\text { Active } \\
\text { Length } \\
(\mathrm{cm})\end{array}$ & $\begin{array}{l}\text { Total } \\
\text { Length } \\
(\mathrm{cm})\end{array}$ & $\lambda$ & Ao $\left(\mathrm{cm}^{2}\right)$ & $\alpha$ \\
\hline 1 & 100 & 14.0 & 21.5 & 0.135 & 242 & 889 \\
\hline 2 & 200 & 14.0 & 21.5 & 0.269 & 484 & 1778 \\
\hline 3 & 400 & 14.0 & 21.5 & 0.538 & 968 & 3556 \\
\hline
\end{tabular}

The schematic diagram of the experimental testing rig for the heat transfer measurement is shown in Figure 2. A $10 \mathrm{~kW}$ electric heater which could provide hot water up to $80^{\circ} \mathrm{C}$, was used to provide hot water for the PHFHE module. Each time before starting the test, the heater was pre-setted to the required testing hot water condition. As soon as the hot water temperature reached the desired testing value, the test was ready to start. In order to remove any particulate matter and avoid blocking the hollow fibres, two micro filters $(5 \mu \mathrm{m})$ for both shell and tube sides were introduced before hot water and cooling water entering into the PHFHE. The hot water feed was then introduced to the shell side of the PHFHE module from the electric heater by a centrifugal pump at a constant flow rate $(0.1-0.61 / \mathrm{min})$ which was controlled by a ball valve. Tap water with the temperature around $14-16 \mathrm{C}$ was used as the cooling water, which passed through the shell side of the PHFHE at constants flow rates (0.2$2.01 / \mathrm{min}$ ) controlled by a ball valve. In all runs, the hot water and cooling water went in counter flow directions. The inlet and outlet temperatures and pressures of two streams were measured by K type thermocouples and pressure sensors (Ge UNIK 5000) with the accuracy of $\pm 0.2 \%$ and $\pm 0.5 \%$ respectively.

The experimental procedures applied for the tests are as following: Firstly the hot water flow rate was maintained at a fixed value, while the cooling water flow rates were varied from 0.2$2.01 / \mathrm{min}$ with $0.21 / \mathrm{min}$ increments. Temperatures of the inlet and outlet of the two streams were recorded every 10 seconds by a DT800Data taker, until two to five subsequent readings did not differ by more than $\pm 0.1^{\circ} \mathrm{C}$. The hot water inlet temperature was varied between $38{ }^{\circ} \mathrm{C}$ to $69^{\circ} \mathrm{C}$, while the cooling water inlet temperature was kept between $14^{\circ} \mathrm{C}$ and $16^{\circ} \mathrm{C}$. 


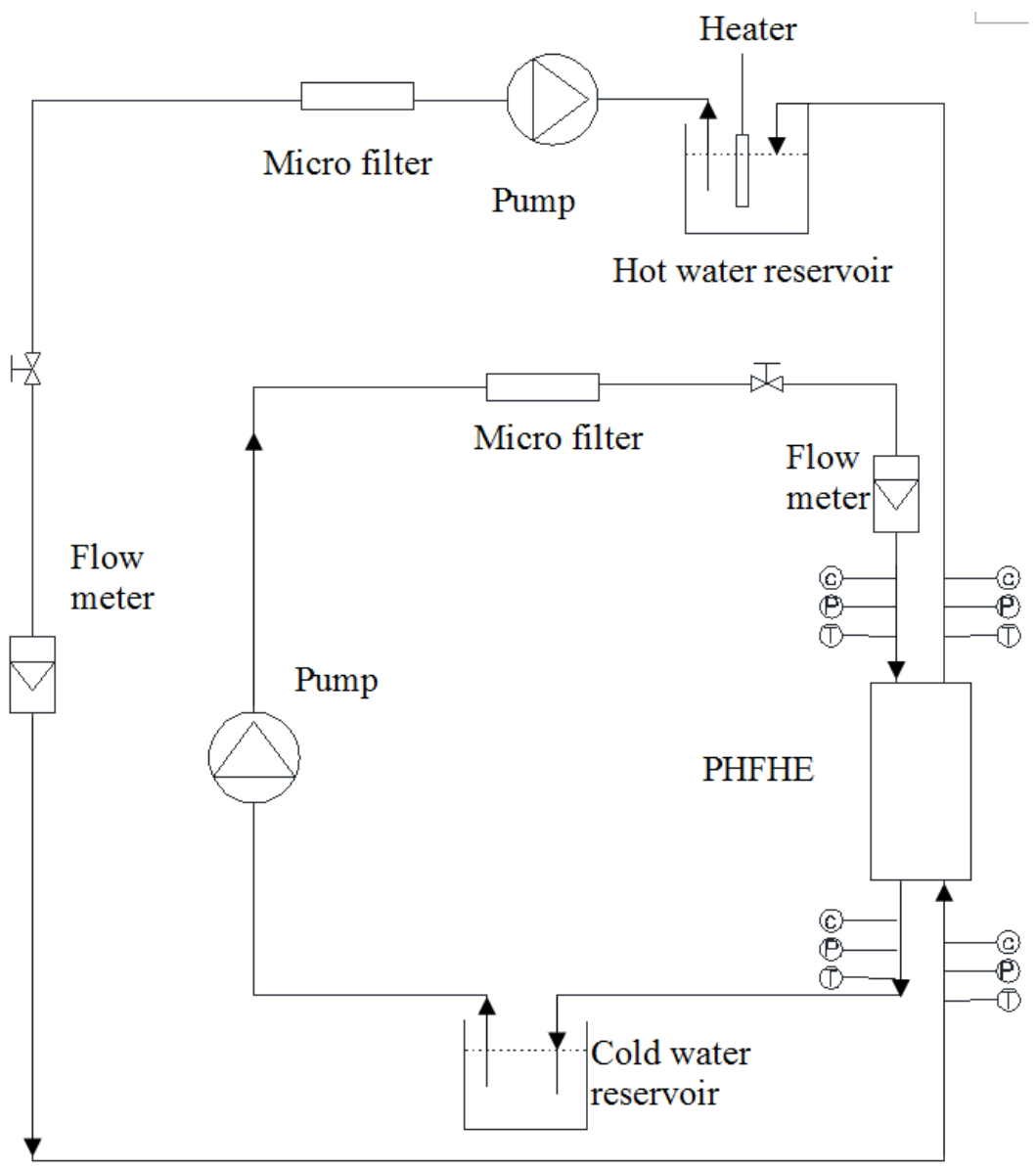

Figure 2 The experimental schematic diagram for heat transfer measurements in PHFHE

\section{Results and Discussion}

In order to obtain the overall heat transfer coefficients, the heat transfer rate $\mathrm{Q}$ should be determined by the mass flow rate and the temperature difference for the tube side or shell side. Figure 3 presents the experimentally obtained overall heat transfer coefficients under the conditions when the tube side flow rate was $0.51 / \mathrm{min}$, and the shell side flow rates were varied between $0.21 / \mathrm{min}$ and $2.01 / \mathrm{min}$. It can be found that when the shell side flow rate is less than $0.81 / \mathrm{min}$, the overall heat transfer coefficient calculated from the thermal capacity change $\mathrm{Q}_{\mathrm{h}}$ of tube side is higher than that calculated from the thermal capacity change $\mathrm{Q}_{\mathrm{c}}$ of shell side. When the shell side flow rate is higher than $0.81 / \mathrm{min}$, the situation is reversed. The difference between the $U$ values calculated from the respective change of the thermal capacity of two streams tends to increase largely as the shell side flow rate increases. However, the difference of the $U$ values obtained by two streams is less than $10 \%$, with the discrepancy being amplified by the fact that very low flow rate was applied in the tube side. As the shell side is well thermally insulated, heat loss may have a smaller effect on this discrepancy. So, in order to compensate and reduce the discrepancy, the average $Q$ values between the two streams are used for the following analysis and discussions, as presented in the rest of the paper. 


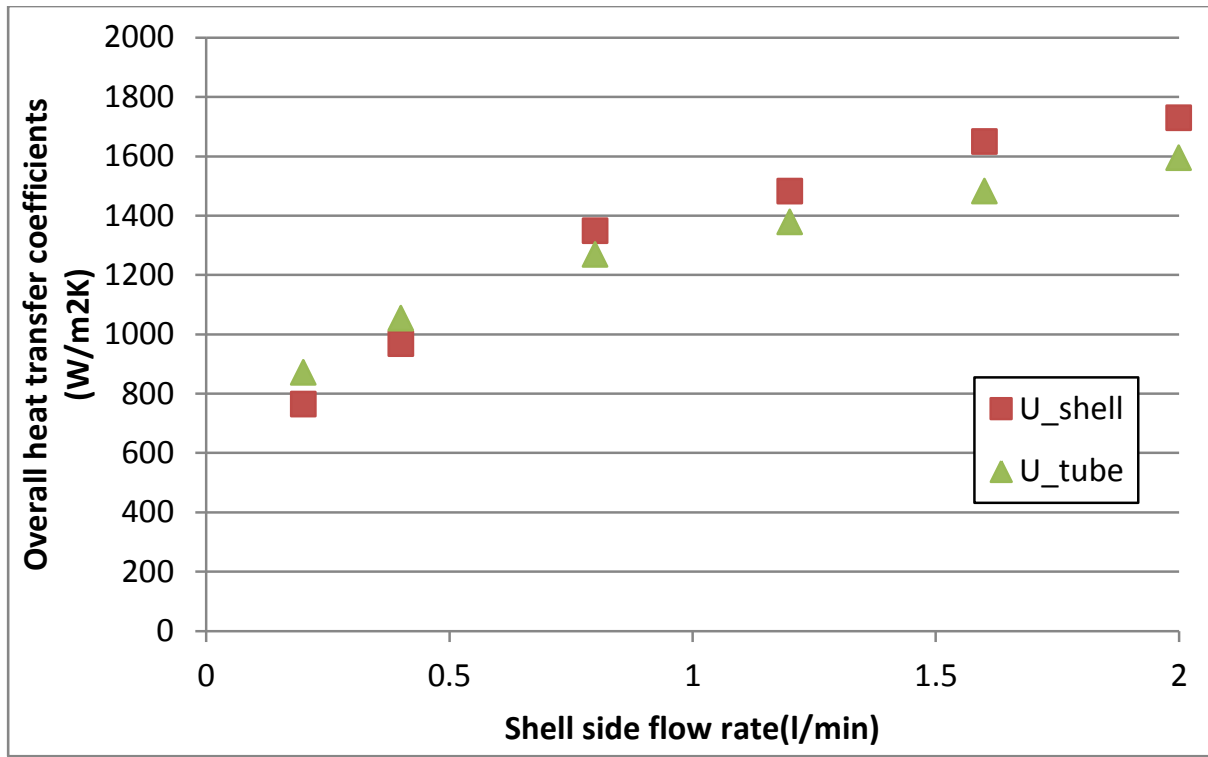

Figure 3 Experimental obtained overall heat transfer coefficients based on the shell side stream conditions and tube side stream conditions

Table 2 Representative experimental testing data for the heat transfer measurement of PHFHE

\begin{tabular}{|c|c|c|c|c|c|c|c|c|c|}
\hline $\begin{array}{l}\text { Th,i } \\
\left({ }^{\circ} \mathrm{c}\right)\end{array}$ & $\begin{array}{l}\text { Th,o( } \\
\text { c) }\end{array}$ & $\begin{array}{l}\text { Tc,i } \\
\left({ }^{\circ} \mathrm{C}\right)\end{array}$ & $\begin{array}{l}\text { Tc,o } \\
\left({ }^{\circ} \mathrm{C}\right)\end{array}$ & $\dot{m}_{t}(1 / \mathrm{min})$ & $\dot{m}_{s}(1 / \min )$ & $\begin{array}{l}\mathrm{U}_{\mathrm{o}} \\
\left(\mathrm{W} / \mathrm{m}^{2} \mathrm{~K}\right)\end{array}$ & $\varepsilon$ & NTU & $\begin{array}{l}\text { HTU } \\
(\mathrm{cm})\end{array}$ \\
\hline \multicolumn{10}{|c|}{ Module $1 \mathrm{~N}=100$} \\
\hline 49.4 & 23.9 & 14.9 & 19.0 & 0.3 & 2.0 & 1675 & 0.741 & 1.461 & 18.9 \\
\hline 42.3 & 26.8 & 13.5 & 18.9 & 0.5 & 1.6 & 1609 & 0.539 & 0.860 & 26.0 \\
\hline 51.9 & 41.6 & 15.6 & 35.3 & 0.4 & 0.2 & 767 & 0.711 & 1.235 & 19.7 \\
\hline \multicolumn{10}{|c|}{ Module 2 N=200 } \\
\hline 69.8 & 43.8 & 15.6 & 39.4 & 0.55 & 0.6 & 857 & 0.478 & 0.884 & 29.3 \\
\hline 57.1 & 33.5 & 15.2 & 29.6 & 0.55 & 1.0 & 1010 & 0.562 & 1.042 & 24.9 \\
\hline 44.7 & 17.3 & 15.0 & 20.2 & 0.2 & 1.9 & 1021 & 0.921 & 2.84 & 15.3 \\
\hline \multicolumn{10}{|c|}{ Module $3 \mathrm{~N}=400$} \\
\hline 52.0 & 19.2 & 13.9 & 23.4 & 0.5 & 2.0 & 1138 & 0.862 & 2.384 & 5.9 \\
\hline 46.4 & 14.4 & 14.2 & 16.6 & 0.1 & 0.2 & 258 & 0.991 & 5.065 & 2.8 \\
\hline 65.4 & 31.2 & 28.1 & 37.5 & 0.3 & 1.2 & 741 & 0.550 & 1.818 & 7.7 \\
\hline
\end{tabular}

We select some typical testing data for the heat transfer measurement of PHFHE and summarize them in Table 2. These includes the hot water and cooling water inlet and outlet temperature, the mass flow rate of the two streams, the calculated total heat transfer rate, and the overall heat transfer coefficient, the heat exchanger effectiveness, the number of transfer unit (NTU) and the height of transfer unit (HTU). We can see that the overall heat transfer coefficients for such PHFHE device could reach up to $1675 \mathrm{~W} / \mathrm{m}^{2} \mathrm{~K}$ for a piece of tubing with shell side diameter of $15 \mathrm{~mm}$ and length of $14 \mathrm{~cm}$. In the literature ${ }^{36}$, the designed value for tubular metal heat exchanger is around $1100-1400 \mathrm{~W} / \mathrm{m}^{2} \mathrm{~K}$, which is even lower than the experimental testing results of such PHFHE device. Inspection of the data in Table 2 also shows that the high value of effectiveness and NTU, up to 0.991 and 5.065 respectively, could be achieved for such PHFHE device. These values correspond to a very small HTU of 
only $2.8 \mathrm{~cm}$, which is in good agreement with HTU obtained in microporous fibre membranebased separation process ${ }^{37}$.

288

289

290

291

292

293

294

295

296

297

298

299

300

301

302

303

304

305

306

307

308

309

310

311

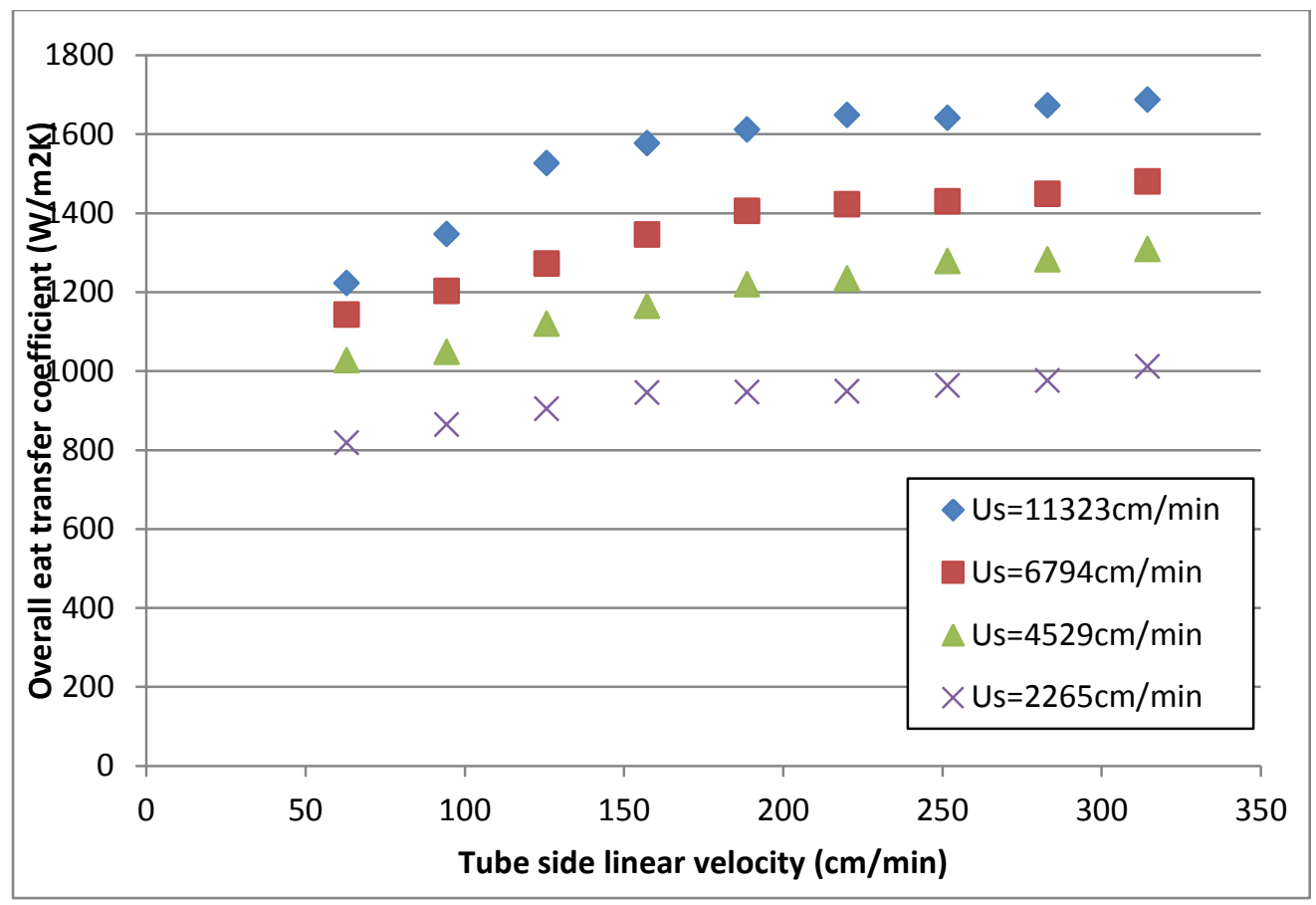

Figure 4 Variations of experimental obtained overall heat transfer coefficients with respect to various tube side liner velocities (Module 1 , hot water inlet temperature $48.5^{\circ} \mathrm{C}$ )

In order to understand the relationship between the overall heat transfer coefficient and the fluid velocity in both shell and tube side, we present the variations of $U$ value with tube side linear velocities when the shell side linear velocity changes from $2265 \mathrm{~cm} / \mathrm{min}$ to $11323 \mathrm{~cm} / \mathrm{min}$. We can find from Figure 4 that higher tube side linear velocity will contribute to better overall heat transfer coefficient when the shell side linear velocity is at fixed value. For instance, for shell side linear velocity at $6794 \mathrm{~cm} / \mathrm{min}$, the overall heat transfer coefficient increases about $1.8 \%$ from $1405 \mathrm{~W} / \mathrm{m}^{2} \mathrm{~K}$ to $1430 \mathrm{~W} / \mathrm{m}^{2} \mathrm{~K}$ when the tube side linear velocity increases from $188 \mathrm{~cm} / \mathrm{min}$ to $252 \mathrm{~cm} / \mathrm{min}$. Moreover, a common feature can be observed is that when the tube side linear velocity increases, the $U$ value reaches a plateau quickly. The plateau $\mathrm{U}$ value is around $1600 \mathrm{~W} / \mathrm{m}^{2} \mathrm{~K}$ for the shell side linear velocity of $11323 \mathrm{~cm} / \mathrm{min}$, and $1000 \mathrm{~W} / \mathrm{m}^{2} \mathrm{~K}$ for the shell side linear velocity of $2265 \mathrm{~cm} / \mathrm{min}$. When the tube side linear velocity is below $150 \mathrm{~cm} / \mathrm{min}$, the heat transfer coefficient seems to follow a linear dependence with respect to tube side linear velocity. We can introduce Gz number to help us better understand the mechanism. According to Hewitt et al. ${ }^{33}, \mathrm{Gz}$ is a non-dimensional group applicable mainly to transient heat conduction in laminar pipe flow. Gz represents the ratio of the time taken by heat to diffuse radially into the fluid by conduction to the time taken for the fluid to reach distance. By calculating the Gz number according to Equation (11), we can see that the $\mathrm{Gz}$ number is in the range of 10 to 53 when the tube side linear velocity increases from $63 \mathrm{~cm} / \mathrm{min}$ to $315 \mathrm{~cm} / \mathrm{min}$ (the same range as shown in Figure 4). As stated by Hewit et al. ${ }^{33}$, small values of $\mathrm{Gz}(\mathrm{Gz}<20)$ indicates that radial temperature profiles are fully developed inside the laminar flow tube. This means that when Gz number and tube side linear 
velocity are at lower values, forced convection is not the only mechanism for heat transfer, heat transfer by natural convection in the radial direction becomes more dominant.

Figure 5 presents the variations of $U$ value to the various shell side linear velocities for PHFHE module 1 . We can find that the $U$ value will increase as the shell side linear velocity improves from $1132 \mathrm{~cm} / \mathrm{min}$ to $11320 \mathrm{~cm} / \mathrm{min}$. Similarly to Figure 4 , after the shell side linear velocity reaches to $11000 \mathrm{~cm} / \mathrm{min}$, the $\mathrm{U}$ value maintains at a stale value for most of the cases. For instance, when tube side linear velocity is fixed at $126 \mathrm{~cm} / \mathrm{min}$ and $63 \mathrm{~cm} / \mathrm{min}$, the plateau value of $U$ is around $1600 \mathrm{~W} / \mathrm{m}^{2} \mathrm{~K}$ and $1250 \mathrm{~W} / \mathrm{m}^{2} \mathrm{~K}$ respectively.

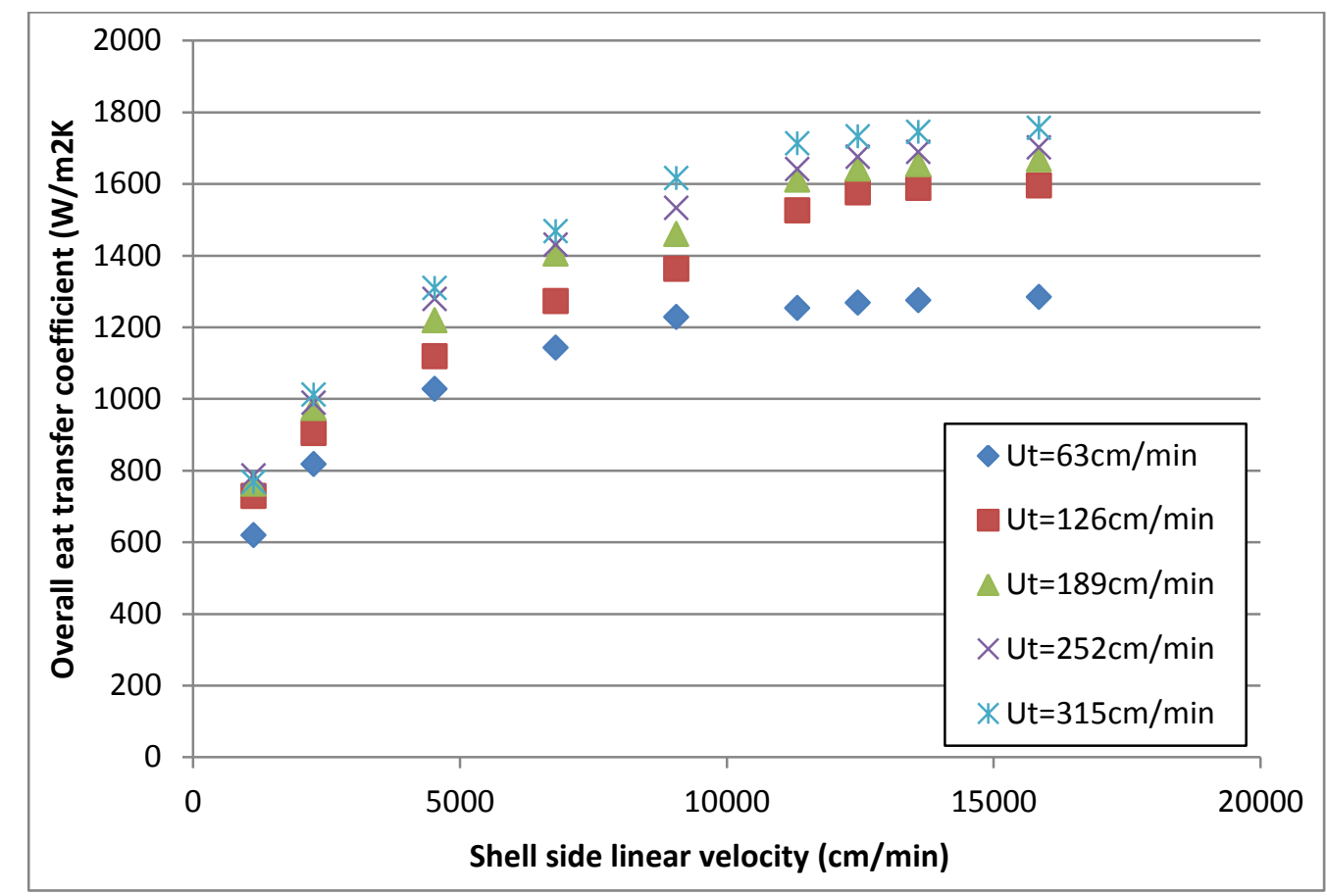

Figure 5 Variations of experimental obtained overall heat transfer coefficients with respect to various shell side liner velocities (Module 1 , hot water inlet temperature $48.5^{\circ} \mathrm{C}$ )

Figure 6-8 depict the variations of overall effectiveness, NTU and HTU of PHFHE with respect to various shell side Reynolds numbers. We can find from Figure 8 that higher shell side Reynolds number will lead to higher overall effectiveness when the tube side Reynold is at fixed value. For instance, at the tube side Reynolds number of 104, the overall effectiveness changes from 0.773 to 0.793 when the shell side Reynolds number increases from 863 to 1151 . Figure 6 also reveals that at fixed shell side Reynolds number, the overall effectiveness will decrease as the tube side Reynolds number increases. For example, at shell side Reynolds number of 576, the overall effectiveness decreases from 0.597 to 0.5 when the tube side Reynolds number increases from 156 to 207. Figure 7 shows that for most of the cases (about 83\%), the NTU is higher than 1. As the PHFHE device mainly operates in laminar flow regime, Figure 7 also reveals that high NTU can be obtained at low tube side Reynolds number, which is in good agreement with the heat transfer literature ${ }^{38}$. Inspection of Figure 6 and 7 also shows that, the overall effectiveness first decreases and then increases as the shell side Re number improves. The reason is because that, according to Eq. (5), the effectiveness is proportional related to $\mathrm{C}_{\min }$, which is the minimum product of the flow rate 
multiple by $\mathrm{Cp}$ for shell side and tube side. At lower shell side $\operatorname{Re}$ number $(\operatorname{Re}, \mathrm{s}=144)$ and higher tube side Re number ( $R e, t>156)$, the effect of shell side flow rate on the effectiveness is more dominant. As the shell side Re number becomes higher than the tube side Re number, the effectiveness is more dependent on tube side Re number. That is why there is a small fluctuation at lower shell side Re number.

From Figure 6-8, we can see that high value of heat exchanger effectiveness and NTU, 0.932 and 0.822 respectively, could be achieved at the tube side Reynolds number of 52 and shell side Reynolds of 1439. However, inspection of Figure 6-8 further indicates that relatively low effectiveness and NTU values, accompanied by high HTU also exist. This means that the rating of the PHFHE device is rather important. In order to achieve higher effectiveness and better thermal performance, the rating of PHFHE device should be performed properly.

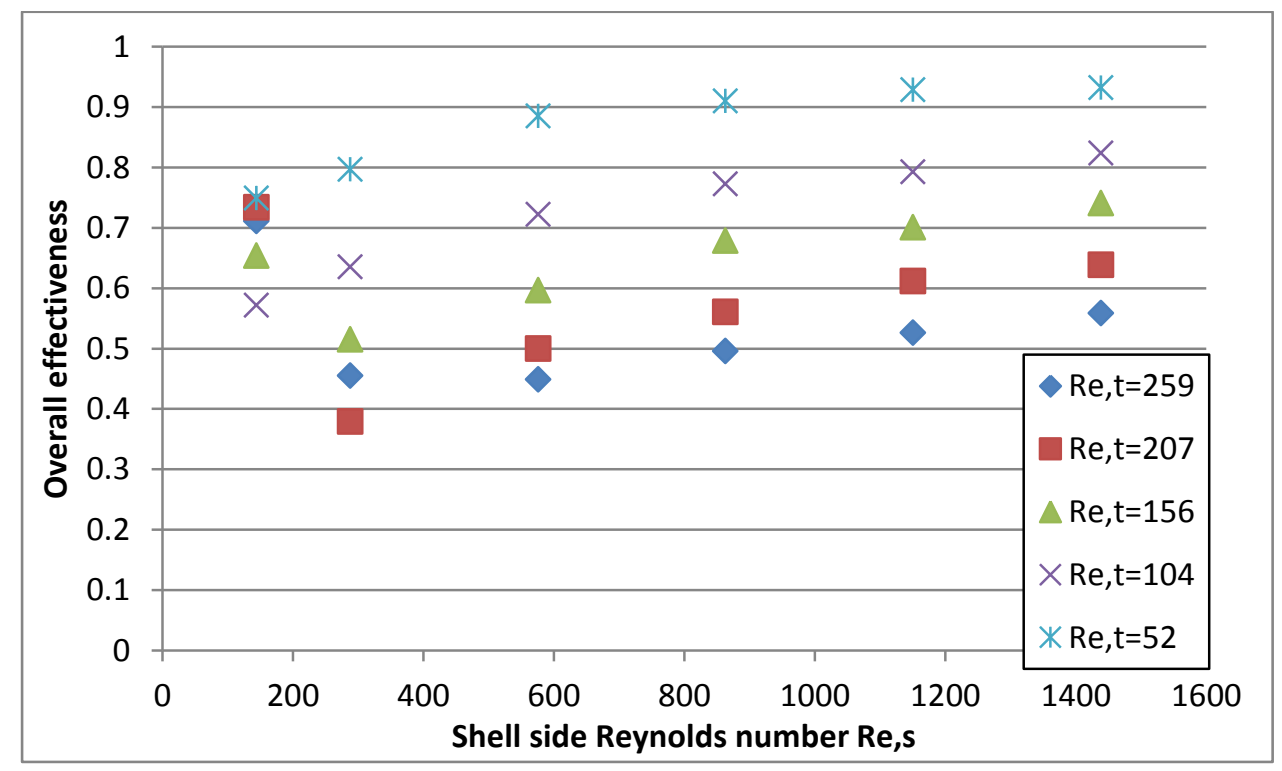

Figure 6 Variations of overall effectiveness with respect to various shell side Reynolds number (Module 1, hot water inlet temperature $48.5^{\circ} \mathrm{C}$ )

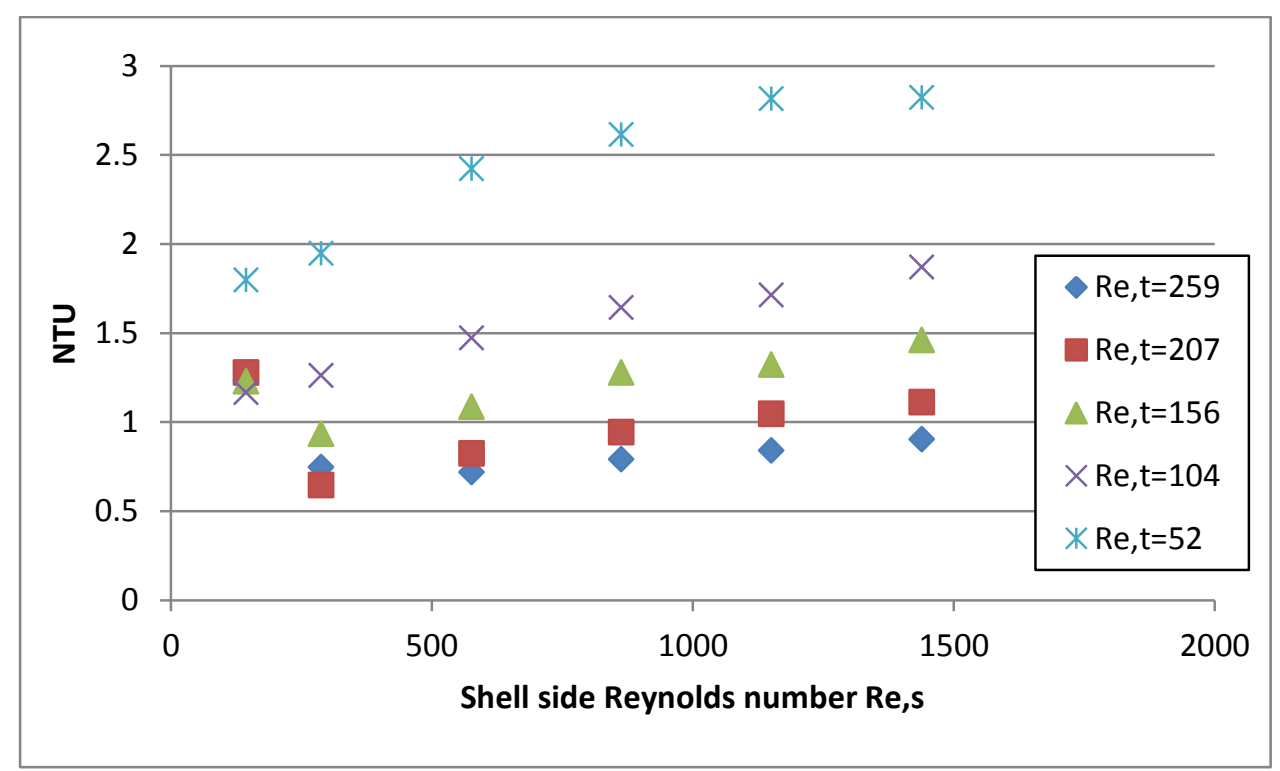


Figure 7 Variations of NTU with respect to various shell side Reynolds number (Module 1, hot water inlet temperature $48.5^{\circ} \mathrm{C}$ )

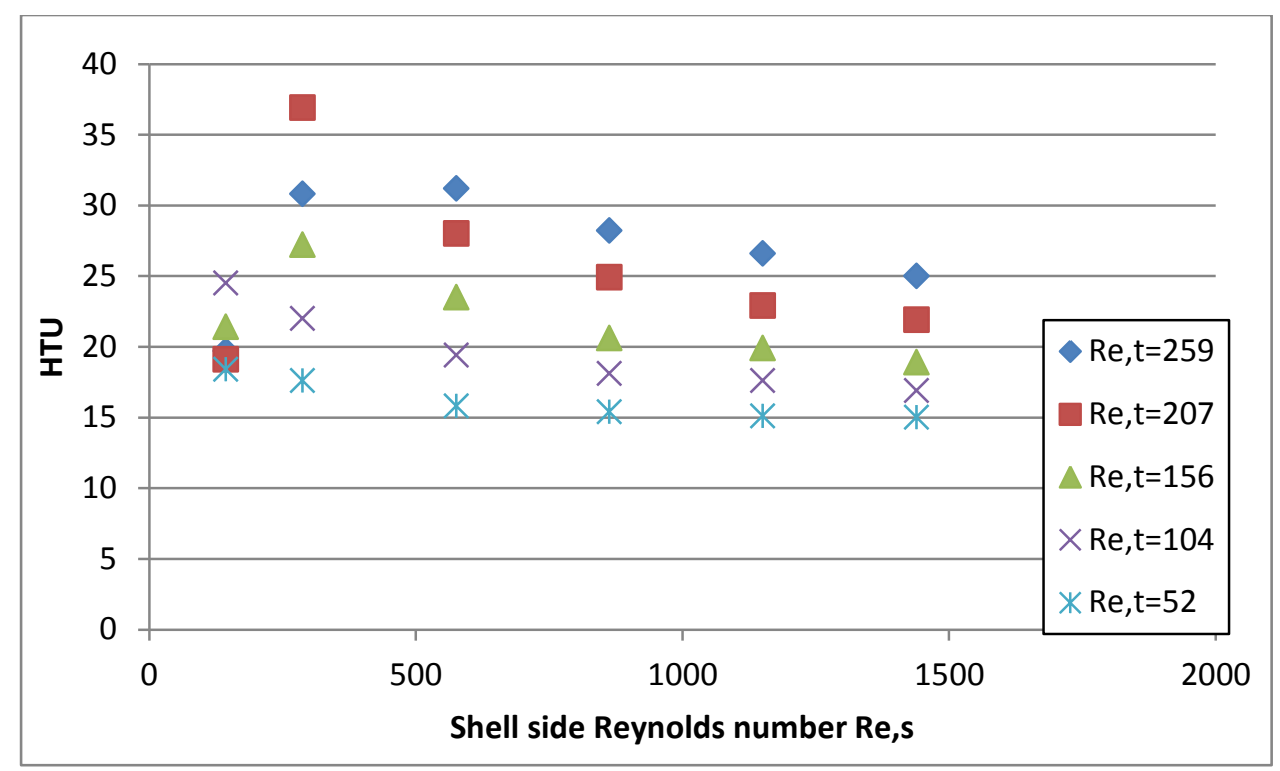

Figure 8 Variations of HTU with respect to various shell side Reynolds number (Module 1, hot water inlet temperature $48.5^{\circ} \mathrm{C}$ )

Figure 9-11 show the comparisons of overall heat transfer coefficients, heat transfer rate and LMTD for different fibre numbers under various shell side Reynolds numbers, at fixed tube side Reynolds number. It can be found that at the same shell and tube side Reynolds number, the module with smaller fibre number produces higher overall heat transfer coefficient. For instance, at shell side Reynolds number of 288 , the overall heat transfer coefficient decreases from $817.6 \mathrm{~W} / \mathrm{m}^{2} \mathrm{~K}$ to $523.5 \mathrm{~W} / \mathrm{m}^{2} \mathrm{~K}$, till $481.9 \mathrm{~W} / \mathrm{m}^{2} \mathrm{~K}$ as the fibre number changes from 100 , 200 to 400 . The reason can be referred to Equation (2), the U value is closely related to the total heat transfer rate $\mathrm{Q}, \Delta \mathrm{T}_{\mathrm{lm}}$, and the heat transfer area $\mathrm{A}$. As shown in Figure 10, at shell side Reynolds number of 288, when the fibre number increases from 100 to 200, the total heat transfer rate increases about $29.1 \%$ from $214.8 \mathrm{~W}$ to $277.3 \mathrm{~W}$. Figure 11 indicates that at the same condition, $\Delta \mathrm{T}_{1 \mathrm{~m}}$ decreases about $0.7 \%$ from $11.6{ }^{\circ} \mathrm{C}$ to $9.9^{\circ} \mathrm{C}$, as the fibre number increases from 100 to 200 . In the meantime, the total heat transfer area improves twice as the fibre number increase from 100 to 200. Compares the abovementioned percentage difference, we can see that the change of fibre numbers plays more dominant role on the overall heat transfer coefficients. Therefore, the increase of fibre number will lead to the decrease of overall $\mathrm{U}$ value. This is also the reason as $\mathrm{U}$ value deceases when the fibre number increases with the variations of tube side Reynolds number, as shown in Figure 12.

Inspection of Figure 9-11 further reveals an interesting phenomenon: at lower shell side flow rate, the heat transfer rate stays very close for $\mathrm{N}=200$ and $\mathrm{N}=100$, while there is a much bigger difference for $\mathrm{N}=400$ and $\mathrm{N}=200$. For instance, at shell side Re number of 288 , the $\mathrm{Q}$ value increases about $29.1 \%$ from $214.8 \mathrm{~W} / \mathrm{m}^{2} \mathrm{~K}$ to $277.3 \mathrm{~W}$ as the fibre number increases from 100 to 200 , while it soars about $64.2 \%$ from $277.3 \mathrm{~W}$ to $605.6 \mathrm{~W}$ as the fibre number improves from 200 to 400 . On the other hand, at lower shell side flow rate, the overall heat 
transfer rate for $\mathrm{N}=200$ and $\mathrm{N}=400$ are approaching each other, while there is a big gap between $\mathrm{N}=100$ and $\mathrm{N}=200$. Hence, when we design the PHFHE device, the fibre numbers should be selected properly in order to maintain effective heat transfer while making full uses of the fibre materials.

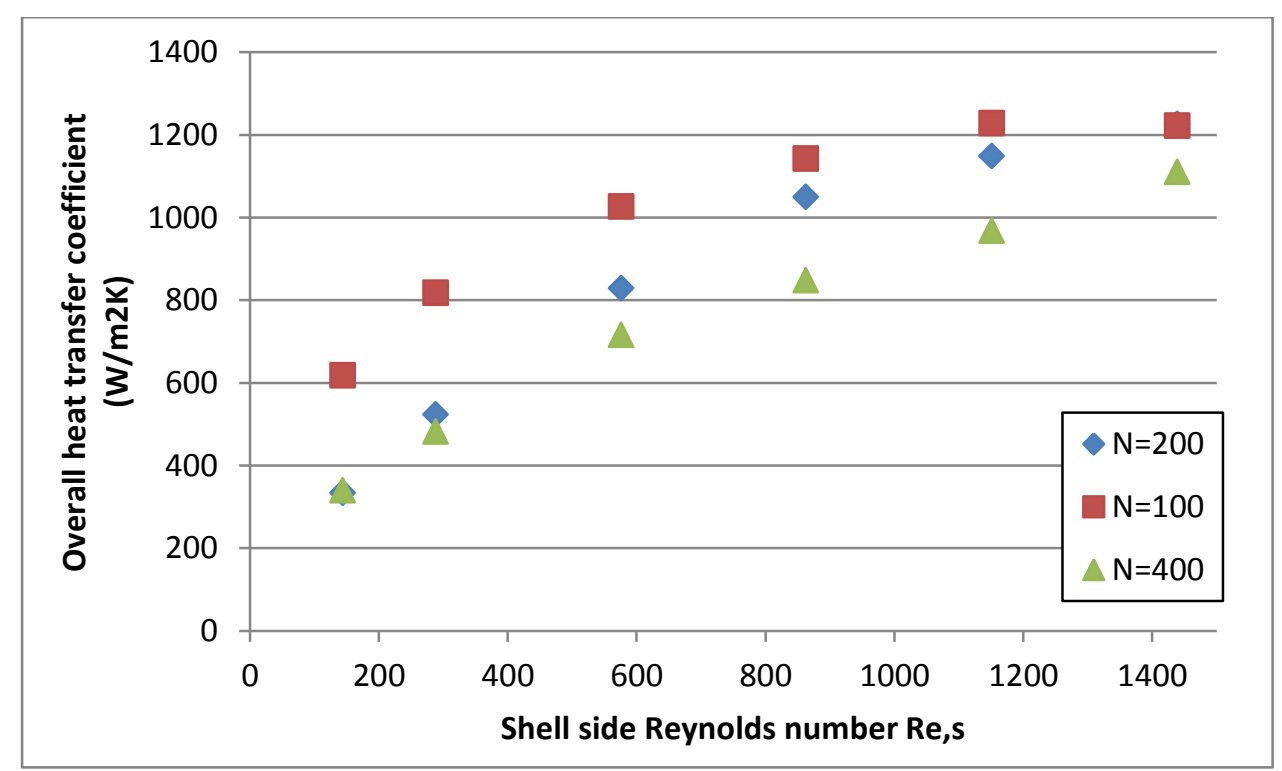

Figure 9 Comparisons of overall heat transfer coefficients for Module 1-3 under various shell side flow rate and at fixed tube side Reynolds number

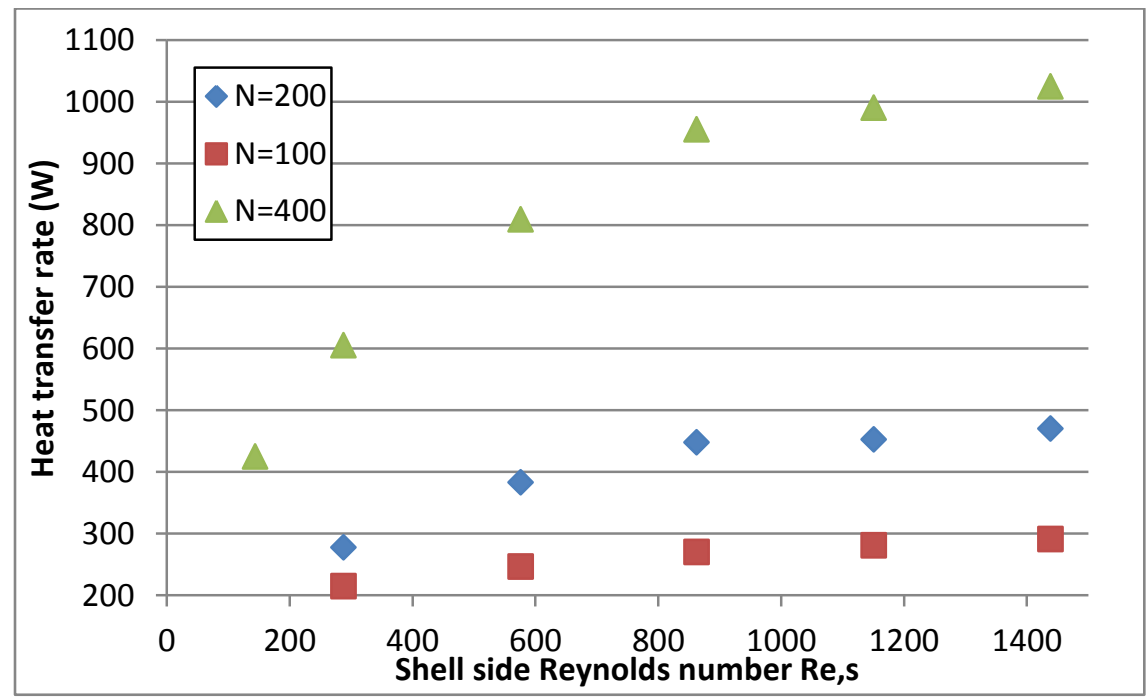

Figure 10 Comparisons of heat transfer rate for Module 1-3 under various shell side flow rate and at fixed tube side Reynolds number 


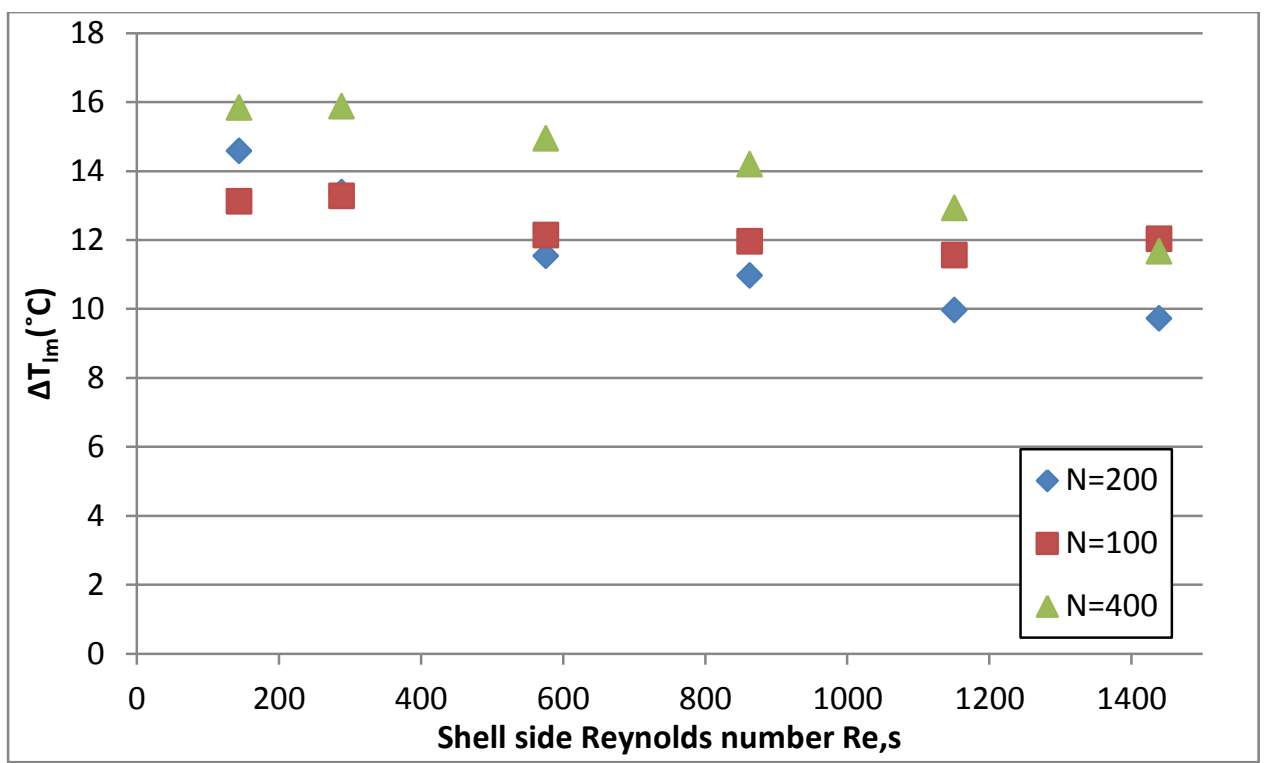

Figure 11 Comparisons of $\Delta \mathrm{T}_{\mathrm{lm}}$ for Module 1-3 under various shell side flow rate and at fixed 394 tube side Reynolds number

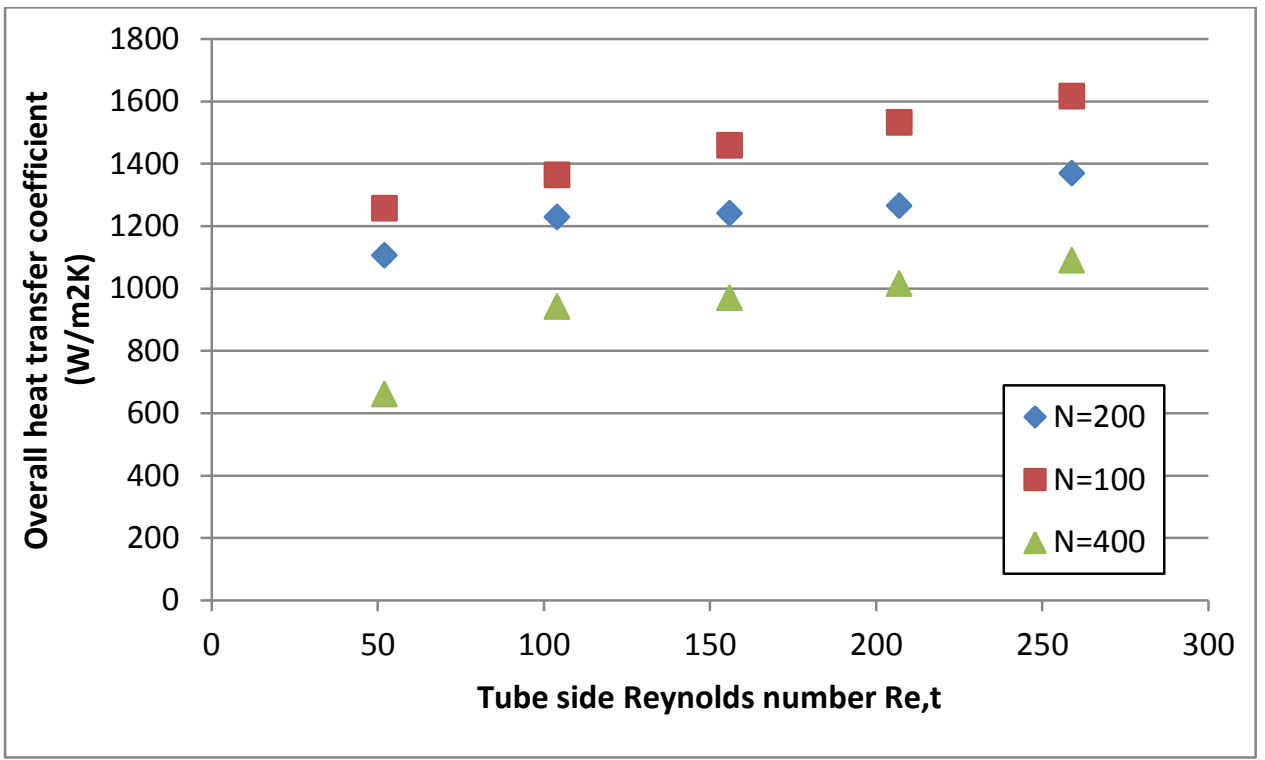

Figure 12 Comparisons of overall heat transfer coefficients for Module 1-3 under various tube side flow rate and at fixed shell side flow rate of $1.61 / \mathrm{min}$

Table 3 Percentage contribution of tube side, shell side and fibre wall resistance to the overall resistance

\begin{tabular}{|c|c|c|c|c|}
\hline Module & Fibre number & Rt/Rov(\%) & Rs/Rov (\%) & Rw/Rov (\%) \\
\hline 1 & 100 & $4-10$ & $35-56$ & $18-31$ \\
\hline 2 & 200 & $3-8$ & $38-62$ & $15-28$ \\
\hline 3 & 400 & $2-7$ & $40-66$ & $13-25$ \\
\hline
\end{tabular}

400 Table 3 presents the percentage contribution of the three major resistances to the overall 401 resistance. The results indicate that tube side resistance are the smallest of the three, therefore 402 by increasing the tube-side Reynolds number, little improvement will be achieved for the 
overall heat transfer performance. By increasing the fibre numbers from 100, 200 to 400, the overall heat transfer coefficients tend to decrease accordingly, and the percentage contribution of shell side resistance will play more dominant role.

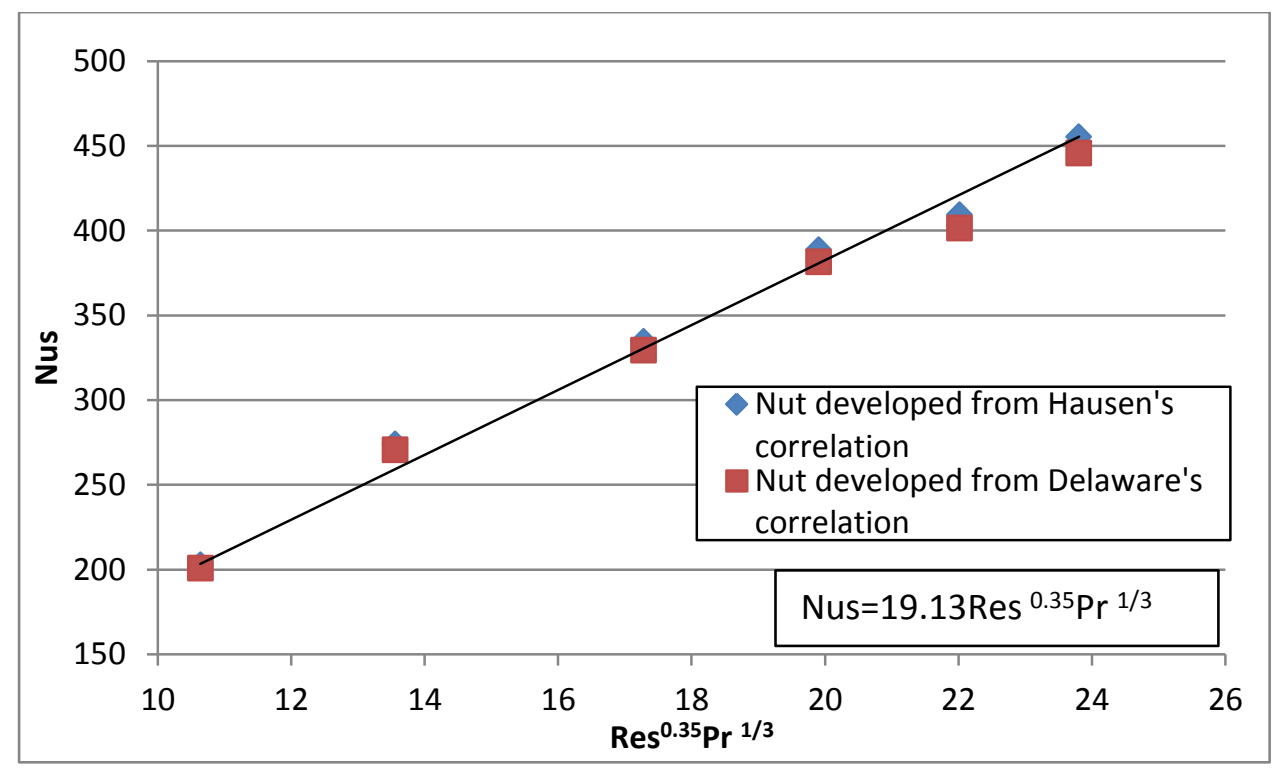

Figure 13 Shell side Nu numbers with respect to Re and Pr number using two different correlations (correlation 1)

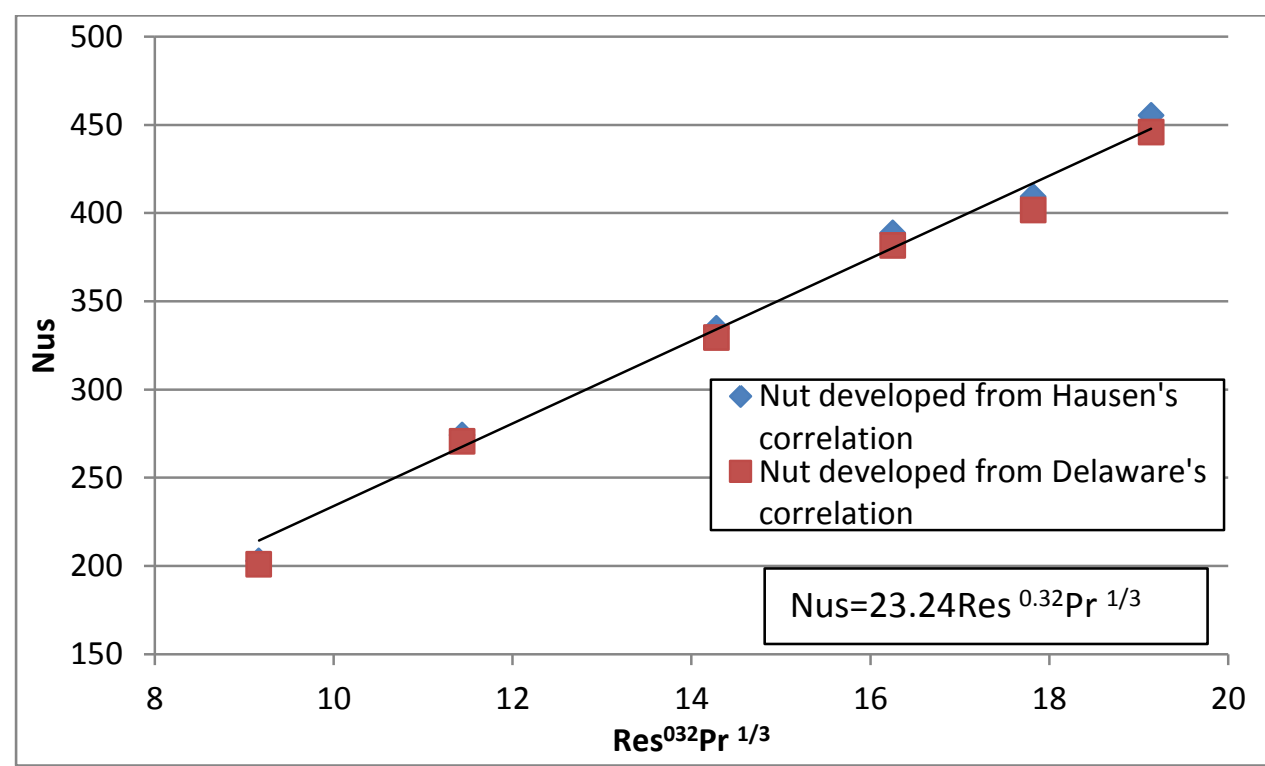

Figure 14 Shell side Nu numbers with respect to Re and Pr number using two different correlations (correlation 2)

Figure 13 and Figure 14 present the relationships between shell side Nu numbers and Re, $\mathrm{Pr}$ number using two different correlations from the literature. Both suitable for laminar flow conditions and validated by various authours ${ }^{39-41}$, Hausen's correlation ${ }^{42}$ and Delaware's correlation $^{35}$ were applied respectively for calculating the tube side heat transfer coefficients. Then, the shell side heat transfer coefficients and the shell side $\mathrm{Nu}$ number could be derived from the experimental obtained overall heat transfer coefficients. The Nu-Re plot shown in 
Figure 13 and Figure 14 indicated very good agreement of shell side Nu numbers using two different correlations. A well correlated equation showing shell side $\mathrm{Nu}$ number as the function of Re and Pr number is also presented respectively in Figure 13 and Figure 14. The difference between the correlation presented in Figure 13 and Figure 14 is the exponent of shell side Re number. Comparing the discrepancy of the correlated equation with results obtained from Hausen's and Delaware correlations, it can be found that the derived correlation 1 with exponent of 0.35 (in Figure 13) is more suitable for shell side Re number less than 200 or larger than 1200 , with the minimum difference of $0.3 \%$. While the derived correlation 2 with exponent of 0.32 (in Figure 14) is more close to results obtained from Hausen's and Delaware correlations (with the minimum difference of $0.14 \%$ ), when the shell side Re number is in the range of 200-1200.

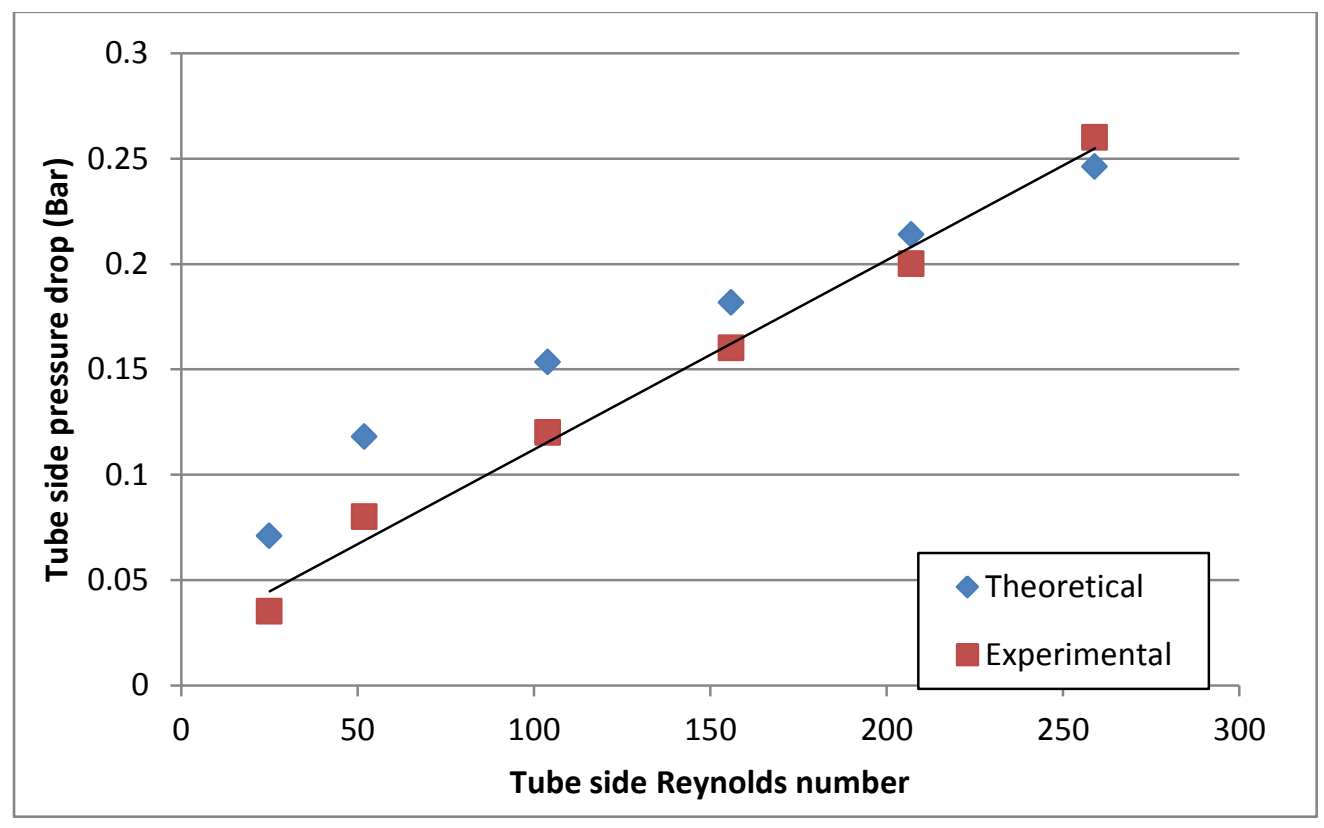

Figure 15 Variations of theoretical and experimental obtained tube side pressure drops under different tube side Re numbers. (Module 1)

Figure 15 shows the comparisons of theoretical and experimental obtained tube side pressure drops under different tube side Re numbers for fibre number $\mathrm{N}=100$. The theoretical tube side pressure drop is calculated using Eq. (12). The experimental tube side pressures of PHFHE are monitored by pressured transducer sensors (GE UNIK 5000). We can see from the diagram that increasing the tube side Re number will result in higher tube side pressure drop. Moreover, a liner relationship could be derived between experimental obtained Re number and tube side pressure drop with $\mathrm{R}^{2}=0.99$. We can also find that the experimental obtained pressure drops are quite close to the theoretical values, with the minimum percentage difference of $5.6 \%$. As the tube sider $\mathrm{Re}$ number increase, the difference between the theoretical and experimental results decreases. 


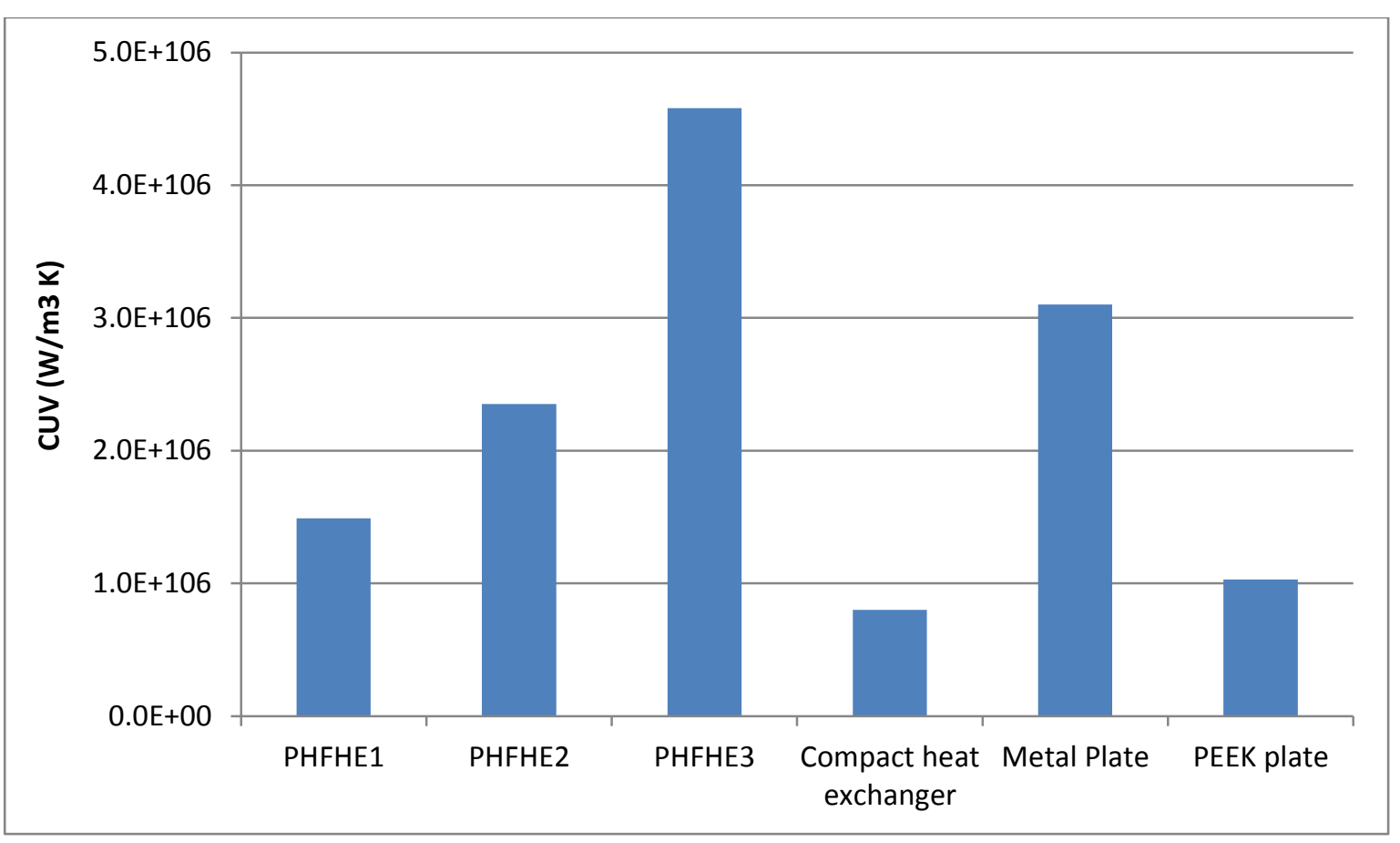

Figure 16 Comparisons of overall conductance per unit volume between PHFHE with conventional heat exchangers

Figure 16 shows the comparisons of overall conductance per unit volume between PHFHEs with conventional metal and plastic heat exchangers. A compact metal heat exchanger with wall thickness of $0.4 \mathrm{~mm}^{43}$, a plate heat exchanger with $0.4 \mathrm{~mm}$ thickness ${ }^{36}$, and a PEEK plate heat exchanger ${ }^{17}$ are chosen for comparisons. We can see from Figure 15 that PHFHE modules generally demonstrate higher CUV values (about 2-8 times) compared with conventional metal and plastic heat exchangers. Despite the relatively low overall heat transfer coefficients, the large surface area to volume ratio of PHFHEs offers controlling factor of performance on a volumetric basis. For instance, for PHFHE module 3 ( fibre number=400), the CUV values are about 7 times higher than the compact tube heat exchanger ${ }^{43}$, and 1.5 times higher than the metal plate heat exchanger ${ }^{36}$. However, the values in Figure 16 for the metal heat exchangers already represent the cutting edge of current technology. While the packing/manufacturing technology for the PHFHEs are currently only subjected to laboratory testing conditions. Hence, we could expect more area to be packed in the PHFHEs, and this will result in even better heat transfer performance and thermal capabilities, which exceeds greatly over the metal counterparts. 


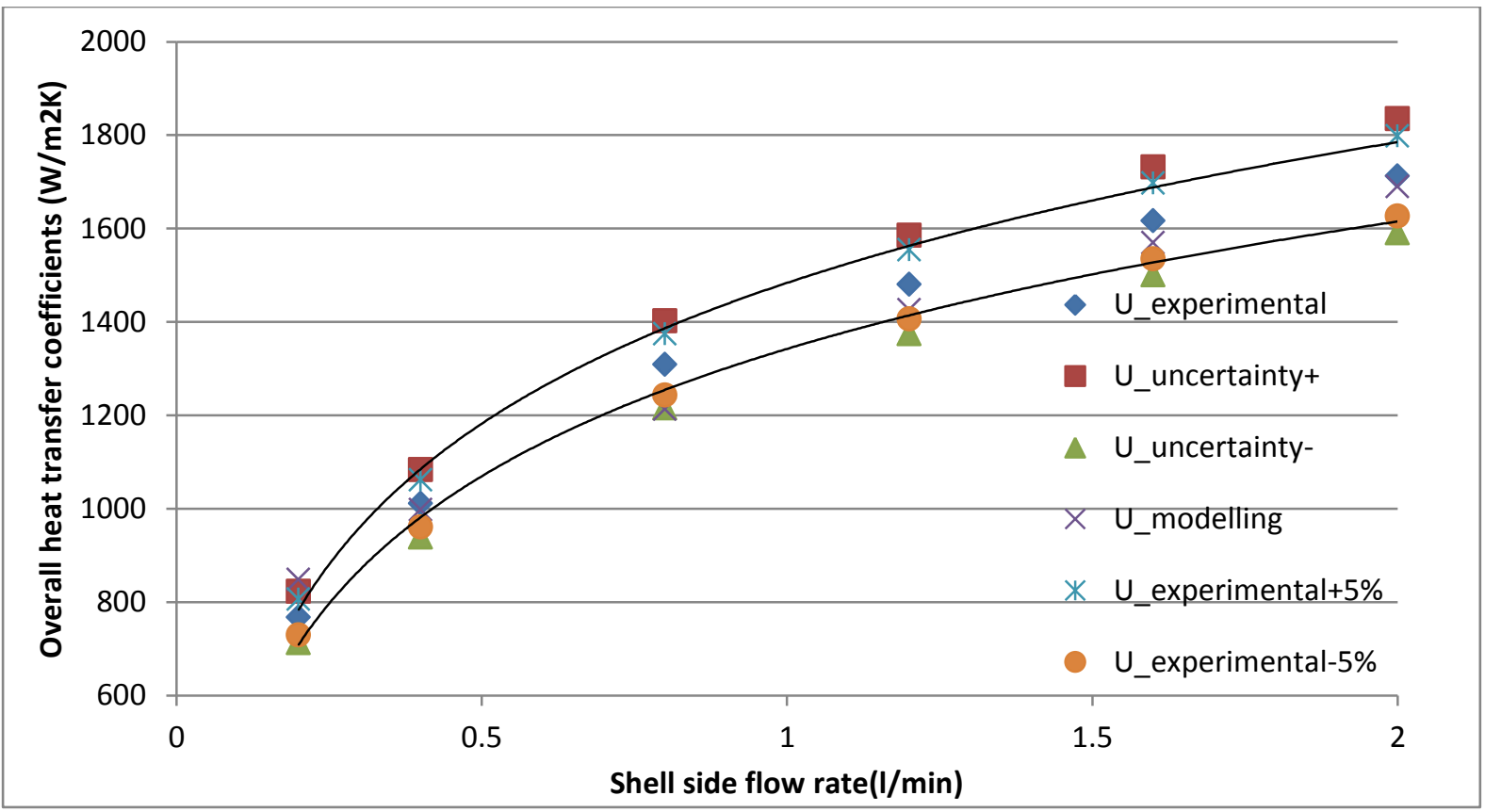

462

463

464

465

466

467

468

469

470

471

472

473

474

475

476

477

478

479

480

481

482

483

484

485

Figure 17 Comparisons of overall heat transfer coefficients obtained from experiments, uncertainty calculations and the modelling results

The uncertainty analysis of the experimental results shown in Figure 17 is performed using the methods proposed by Moffat ${ }^{44}$. Considering all the measurement uncertainties for mass flow rates, temperatures, and fibre diameters, the experimental uncertainties for the overall heat transfer coefficients is between $\pm 7.1 \%$ and $\pm 9.8 \%$. Based on the experimental inlet and outlet streams conditions, the simulation programme developed by the authors was applied and results are presented in Figure 15. We also plot two curves showing the deviations of $\pm 5 \%$ from the experimental obtained results. We can find that, in general, the simulation results fall in good agreement with the experimental data, with differences less than $5 \%$.

\section{Conclusion}

The PP based polymer hollow fibre heat exchangers were manufactured and tested under various shell $(0.2-2.01 / \mathrm{min})$, tube side flow rate $(0.1-0.61 / \mathrm{min})$ and tube side water temperatures $\left(40-70^{\circ} \mathrm{C}\right)$. The maximum experimental obtained overall heat transfer coefficients were achieved in module 1 of PHFHE, with the $U$ values between 1700 $1800 \mathrm{~W} / \mathrm{m}^{2} \mathrm{~K}$. These values are higher than other results reported in literature for water to water applications in polymer hollow fibre heat exchanger.

Three different PHFHE modules with fibre numbers of 100, 200 and 400 were manufactured and the thermal performances were compared in the tests. The experimental obtained overall heat transfer coefficients were $758-1675 \mathrm{~W} / \mathrm{m}^{2} \mathrm{~K}, 369-1453 \mathrm{~W} / \mathrm{m}^{2} \mathrm{~K}$ and $296-1201 \mathrm{~W} / \mathrm{m}^{2} \mathrm{~K}$ respectively for Module 1, 2 and 3. This indicates that module 1 offers higher $U$ value compared with the other two modules.

By changing the tube and shell side flow rate, the effectiveness, NTU and HTU of PHFHE modules are also investigated. With the active length of $14 \mathrm{~cm}$, the module 1 of PHFHE could 
attain high value of effectiveness and NTU, up to 0.991 and 5.065 respectively. The HTU achieved was as low as $2.8 \mathrm{~cm}$, about 35 times less than the lower limit for shell and tube heat exchangers and 20 times lower than typical values for plate heat exchangers. Such results demonstrate that if PHFHE devices could be rated and designed properly, they could achieve relatively high NTU in a single module.

Since the surface area per unit volume in such PHFHEs is quite high, in the range of 880$3600 \mathrm{~m}^{2} / \mathrm{m}^{3}$, their volumetric rate of heat transfer is very high. Comparisons of CUV between PHFHEs and metal heat exchangers reveals that the CUV values of PHFHEs are approximately 2-7 times higher than the metal counterparts. This superior performance can result in potentially more compact designs based on PHFHE devices, for water desalination, solar water heating system, and automotive applications. Therefore, the superior thermal performance, and large heat transfer areas, and the advantages of low price and light weight of polymer materials, make PHFHEs a promising substitute over conventional metal heat recovery system for building application.

\section{Acknowledgement}

The authors would like to acknowledge the financial support and contributions from Innovate UK (project code: 131821).

\section{Reference}

1 Pérez-Lombard, L., Ortiz, J. \& Pout, C. A review on buildings energy consumption information. Energy and Buildings 40, 394-398, doi:http://dx.doi.org/10.1016/j.enbuild.2007.03.007 (2008).

2 Mardiana-Idayu, A. \& Riffat, S. B. Review on heat recovery technologies for building applications. Renewable and Sustainable Energy Reviews 16, 1241-1255, doi:http://dx.doi.org/10.1016/j.rser.2011.09.026 (2012).

3 Shao, L., Riffat, S. B. \& Gan, G. Heat recovery with low pressure loss for natural veltilation. Energy and Buildings 28, 179-184, doi:http://dx.doi.org/10.1016/S0378-7788(98)00016-4 (1998).

4 Zhou, Y. P., Wu, J. Y. \& Wang, R. Z. Performance of energy recovery ventilator with various weathers and temperature set-points. Energy and Buildings 39, 1202-1210, doi:http://dx.doi.org/10.1016/j.enbuild.2006.12.010 (2007).

5 Roulet, C. A., Heidt, F. D., Foradini, F. \& Pibiri, M. C. Real heat recovery with air handling units. Energy and Buildings 33, 495-502, doi:http://dx.doi.org/10.1016/S03787788(00)00104-3 (2001).

6 Nasif, M., Al-Waked, R., Morrison, G. \& Behnia, M. Membrane heat exchanger in HVAC energy recovery systems, systems energy analysis. Energy and Buildings 42, 1833-1840, doi:http://dx.doi.org/10.1016/j.enbuild.2010.05.020 (2010).

7 Mahmud, K., Mahmood, G. I., Simonson, C. J. \& Besant, R. W. Performance testing of a counter-cross-flow run-around membrane energy exchanger (RAMEE) system for HVAC applications. Energy and Buildings 42, 1139-1147, doi:http://dx.doi.org/10.1016/i.enbuild.2010.02.005 (2010).

8 Manz, H. \& Huber, H. Experimental and numerical study of a duct/heat exchanger unit for building ventilation. Energy and Buildings 32, 189-196, doi:http://dx.doi.org/10.1016/S03787788(00)00043-8 (2000). 
5299 Kragh, J., Rose, J., Nielsen, T. R. \& Svendsen, S. New counter flow heat exchanger designed for ventilation systems in cold climates. Energy and Buildings 39, 1151-1158, doi:http://dx.doi.org/10.1016/i.enbuild.2006.12.008 (2007).

10 Dartnall, W. J., Revel, A. \& Giotis, V. Air-Conditioning Employing Indirect Evaporative Cooling Can Be Shown to Derive Its Energy From the Solar Source. ASME Proceedings / Energy Systems: Analysis, Thermodynamics and Sustainability, November 2009, Florida, USA (2009).

11 Kachhwaha, S. S. \& Prabhakar, S. Heat and mass transfer study in a direct evaporative cooler. Journal of Scientific \& Industrial Research 69, 705-710 (2010). Bahadur, R. \& Bar-Cohen, A. Thermal design and optimization of natural convection polymer pin fin heat sinks. Components and Packaging Technologies, IEEE Transactions on 28, 238246 (2005).

13 Bahadur, R. \& Bar-Cohen, A. in Thermal and Thermomechanical Phenomena in Electronic Systems, 2004. ITHERM'04. The Ninth Intersociety Conference on. 268-275 (IEEE).

14 Song, L., Li, B., Zarkadas, D., Christian, S. \& Sirkar, K. K. Polymeric hollow-fiber heat exchangers for thermal desalination processes. Industrial and Engineering Chemistry Research 49, 11961-11977, doi:10.1021/ie100375b (2010).

15 Bourouni, K., Martin, R., Tadrist, L. \& Tadrist, H. Experimental investigation of evaporation performances of a desalination prototype using the aero-evapo-condensation process. Desalination 114, 111-128, doi:http://dx.doi.org/10.1016/S0011-9164(98)00003-4 (1997).

16 Wu, C., Mantell, S. C. \& Davidson, J. Polymers for solar domestic hot water: Long-term performance of PB and nylon 6, 6 tubing in hot water. Journal of solar energy engineering 126, 581-586 (2004).

17 Liu, W., Davidson, J. \& Mantell, S. Thermal analysis of polymer heat exchangers for solar water heating: A case study. Journal of Solar Energy Engineering, Transactions of the ASME 122, 84-91 (2000).

18 Huang, S.-M., Zhang, L.-Z., Tang, K. \& Pei, L.-X. Turbulent Heat and Mass Transfer Across a Hollow Fiber Membrane Tube Bank in Liquid Desiccant Air Dehumidification. Journal of Heat Transfer 134, 082001-082001, doi:10.1115/1.4006208 (2012).

19 Zhang, L.-Z., Huang, S.-M. \& Pei, L.-X. Conjugate heat and mass transfer in a cross-flow hollow fiber membrane contactor for liquid desiccant air dehumidification. International Journal of Heat and Mass Transfer 55, 8061-8072, doi:http://dx.doi.org/10.1016/j.ijheatmasstransfer.2012.08.041 (2012).

20 Chen, X., Su, Y., Reay, D. \& Riffat, S. Recent research developments in polymer heat exchangers - A review. Renewable and Sustainable Energy Reviews 60, 1367-1386, doi:http://dx.doi.org/10.1016/j.rser.2016.03.024 (2016).

21 El-Dessouky, H. T. \& Ettouney, H. M. Plastic/compact heat exchangers for single-effect desalination systems. Desalination 122, 271-289, doi:http://dx.doi.org/10.1016/S00119164(99)00048-X (1999).

22 Hetsroni, G. \& Mosyak, A. Heat transfer and pressure drop in a plastic heat exchanger with triangular channels. Chemical Engineering and Processing: Process Intensification 33, 91-100, doi:http://dx.doi.org/10.1016/0255-2701(94)85007-0 (1994).

23 Wharry Jr, S. R. Fluoropolymer heat exchangers. Metal Finishing 93, 693-704, doi:http://dx.doi.org/10.1016/0026-0576(95)93415-X (1995).

24 Brouwers, H. J. H. \& Van Der Geld, C. W. M. Heat transfer, condensation and fog formation in crossflow plastic heat exchangers. International Journal of Heat and Mass Transfer 39, 391-405, doi:http://dx.doi.org/10.1016/0017-9310(95)00113-N (1996).

25 Bandelier, P., Deronzier, J. C. \& Lauro, F. Plastic heat exchangers. Matériaux \& Techniques 910, 67-70 (1992).

26 Bourouni, K., Martin, R., Tadrist, L. \& Chaibi, M. T. Heat transfer and evaporation in geothermal desalination units. Applied Energy 64, 129-147, doi:http://dx.doi.org/10.1016/S0306-2619(99)00071-9 (1999). 
58027 Zarkadas, D. M., Li, B. \& Sirkar, K. K. in Proceedings of the ASME Summer Heat Transfer $581 \quad$ Conference. 429-438.

58228 Yang, D. et al. Hollow fibers as structured packing for olefin/paraffin separations. Journal of membrane science 279, 61-69 (2006).

29 Yang, D., Le, L., Martinez, R. \& Morrison, M. Hollow fibers structured packings in olefin/paraffin distillation: apparatus scale-up and long-term stability. Industrial \& Engineering Chemistry Research 52, 9165-9179 (2013).

Astrouski I., Raudensky M. \& M., D. Particulate fouling of polymeric hollow fiber heat exchanger. Proceedings of international conference on heat exchanger fouling and cleaning, June 09-14, 2013, Budapest, Hungary (2013).

31 Zhao, J. et al. Numerical simulation of novel polypropylene hollow fiber heat exchanger and analysis of its characteristics. Applied Thermal Engineering 59, 134-141, doi:http://dx.doi.org/10.1016/j.applthermaleng.2013.05.025 (2013).

32 Shah, R. K. Heat exchanger basic design methods. In Low Reynolds number flow heat exchangers, Hemishere Publishing Co. New York (1983).

33 Hewitt, G. F., Shires, G. L. \& Bott, T. R. Process Heat Transfer. CRC Press, Boca Raton, FL, USA. (1994).

34 Mohiuddin Mala, G. \& Li, D. Flow characteristics of water in microtubes. International Journal of Heat and Fluid Flow 20, 142-148, doi:http://dx.doi.org/10.1016/S0142727X(98)10043-7 (1999).

35 Kern, D. Q. Process Heat Transfer. Mcgraw-Hill College; 1St Edition edition (1950).

36 Don W. Green \& Perry, R. H. Perry's Chemical Engineers' Handbook, Eighth Edition. McGrawHill Professional, New York, 2007 (2007).

37 Prasad, R. \& Sirkar, K. Dispersion - free solvent extraction with microporous hollow - fiber modules. AlChE journal 34, 177-188 (1988).

38 Schlundler, E. U. Heat exchanger deisgn handbook. Hemisphere Publishing Co., New York, NY (1983).

39 Chen, L., Sun, Y., Du, X., Wei, G. \& Yang, L. Performance Analysis of Anti-corrosion Heat Exchangers Made of Special Plastics for Flue Gas Heat Recovery. Proceedings of the CSEE 34, 2778-2783 (2014).

40 Zhang, L.-Z. \& Huang, S.-M. Coupled heat and mass transfer in a counter flow hollow fiber membrane module for air humidification. International Journal of Heat and Mass Transfer 54, 1055-1063, doi:http://dx.doi.org/10.1016/i.ijheatmasstransfer.2010.11.025 (2011).

41 Lv, Y., Yu, X., Tu, S.-T., Yan, J. \& Dahlquist, E. Experimental studies on simultaneous removal of $\mathrm{CO} 2$ and $\mathrm{SO} 2$ in a polypropylene hollow fiber membrane contactor. Applied Energy 97, 283-288, doi:http://dx.doi.org/10.1016/j.apenergy.2012.01.034 (2012).

42 Karlsson, H. O. E. \& Trägårdh, G. Heat transfer in pervaporation. Journal of Membrane Science 119, 295-306, doi:http://dx.doi.org/10.1016/0376-7388(96)00150-0 (1996).

43 Taler, D. Prediction of heat transfer correlations for compact heat exchangers. Forschung im Ingenieurwesen 69, 137-150, doi:10.1007/s10010-004-0148-5.

44 Moffat, R. J. Describing the uncertainties in experimental results. Experimental Thermal and Fluid Science 1, 3-17, doi:http://dx.doi.org/10.1016/0894-1777(88)90043-X (1988). 